
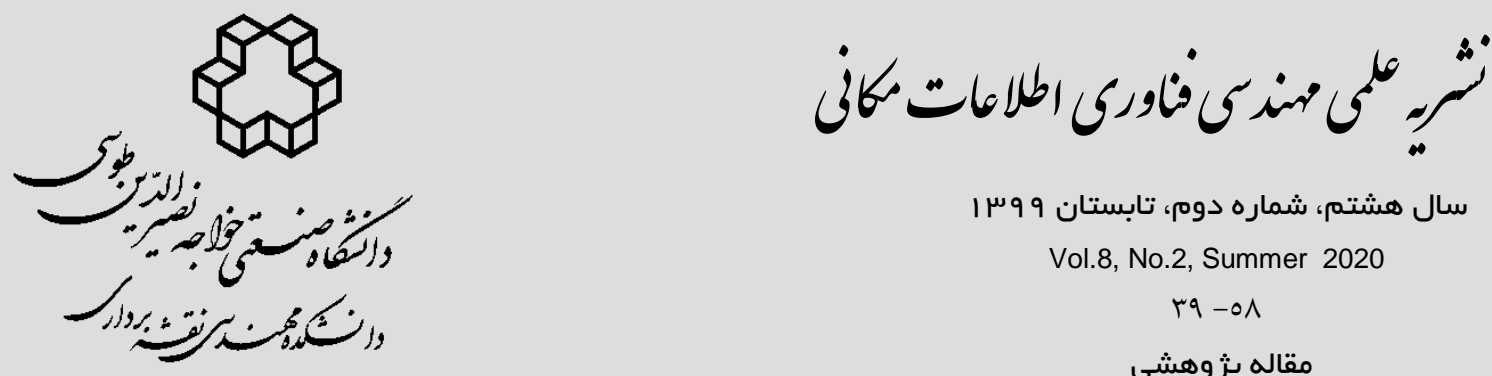

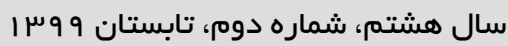
Vol.8, No.2, Summer 2020

rq $-0 \wedge$

مقاله يزّوهشى

معرفى مدل بهينهشده تراكم تاج يوشش جنكًل (FCD) به منظور ارزيابى و پايش مستمر جنكًل هاى هير كانى

\author{
مسعود طايفى فيجانى ':، سعيد آزادنزاد؟

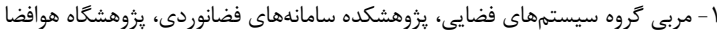

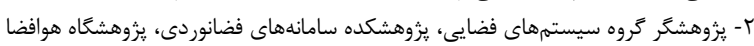

تاريخ دريافت مقاله:

نقشهبردارى از مساحت جنكل يك يِيش نياز براى به دست آوردن اطلاعات كمى و كيفى در مورد جنكلها و و تدوين استراتزىهاى

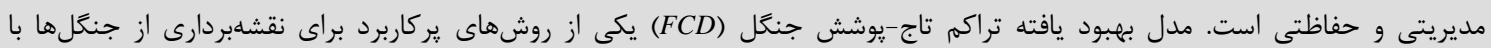

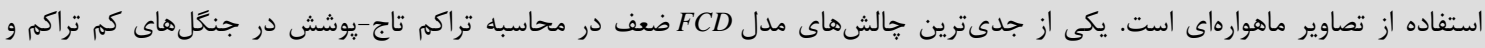

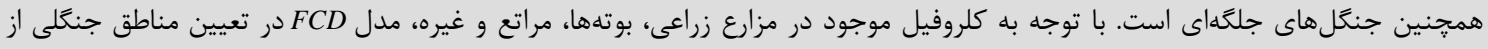

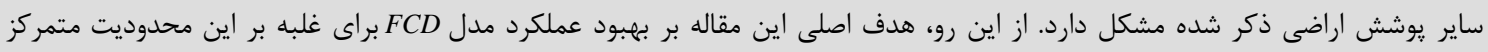

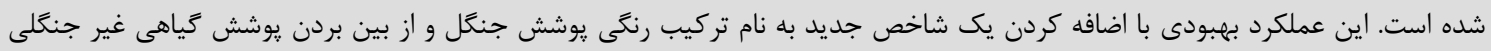

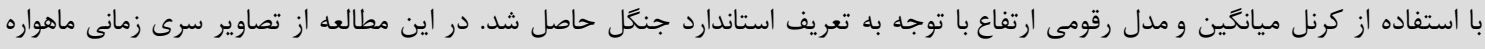

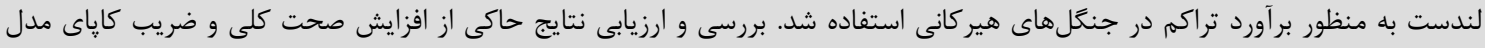

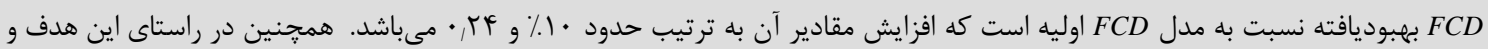

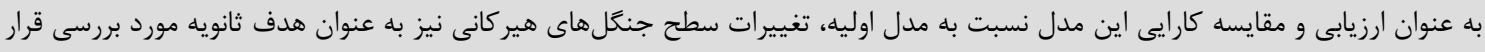

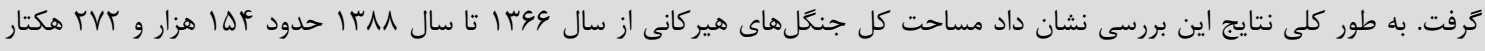

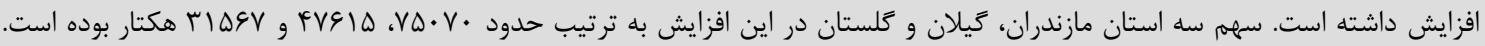

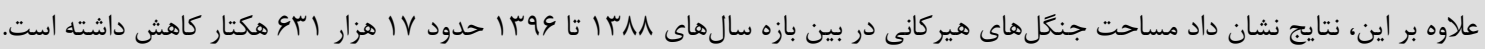

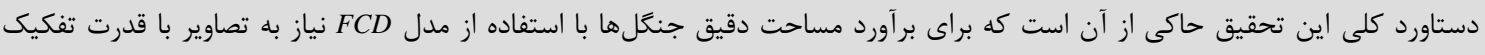
مكانى بسيار بالا مىباشد.

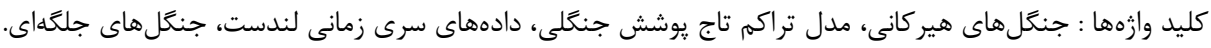


حفظ و حراست و نتحَهداشت و پِايش منابع جنَّلى براى اتكاء و استفاده از ايسن روش كمبـود منــابع و اعتبـارات

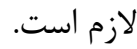

در اين يزوهش روشى كارآ، عمليـاتى و در مقيـاس

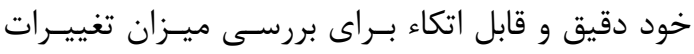

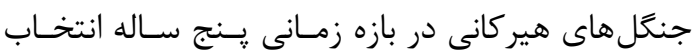

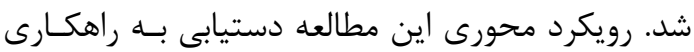

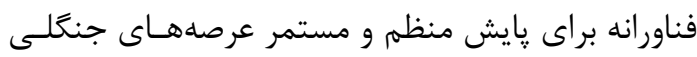

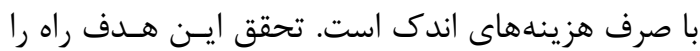
براى پايش منظهم و سالانه عرصـهـهـاى جنَّلـى همــوار

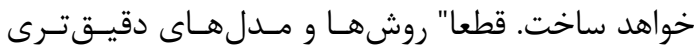

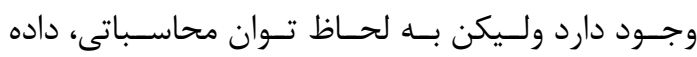
موجـود، اعسم از تصـويرى يـا واقعيـت زمينـى و سـاير

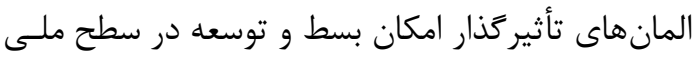

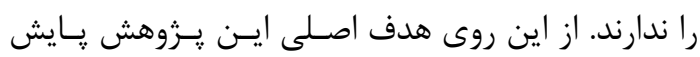
منظم جنغله هاى هير كانى طى سه دها اخيـر (از سـال

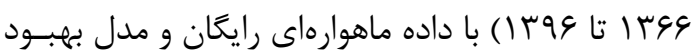
يافته تراكم تاج-يوشش جنكل' (FCD) است.

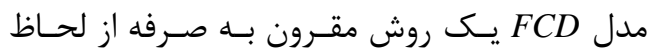

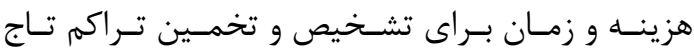

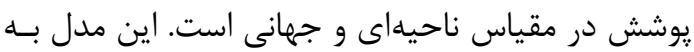

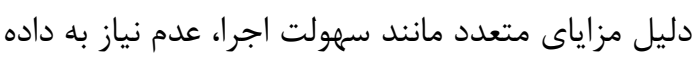

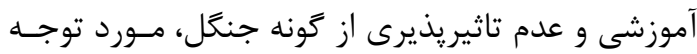

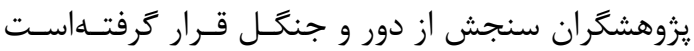

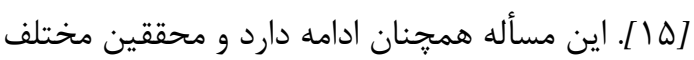

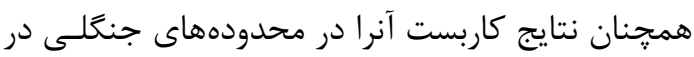

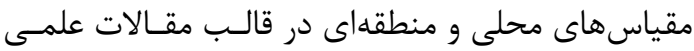

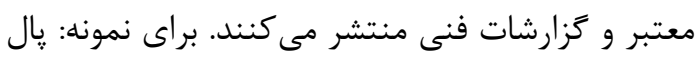

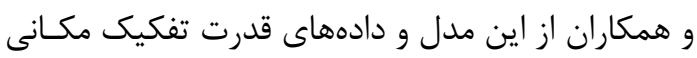

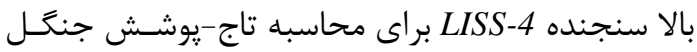

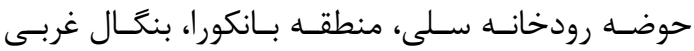

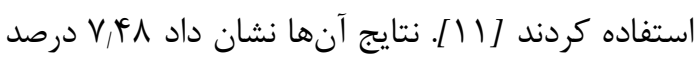

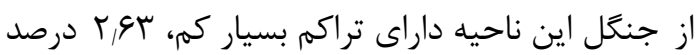

\footnotetext{
${ }^{1}$ Forest Canopy Density
}

- (- مقدمه

جنكل هاى هير كانى با 1,9 ميليون هكتار وسعت، از

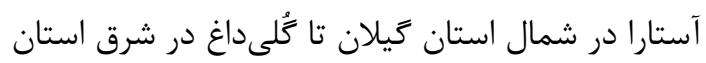

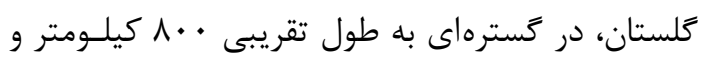

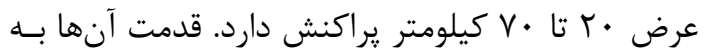

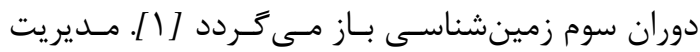

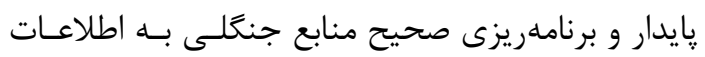

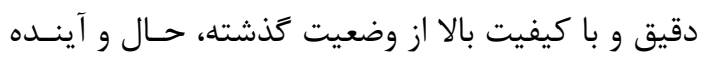
جنكل نيازمند است [ []]. جنكل هــاى شـمال ايــران در

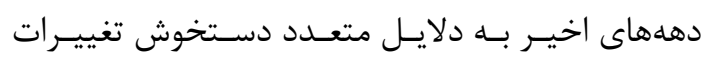

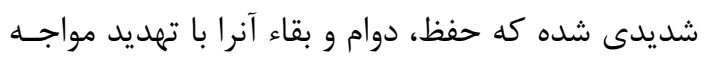
ساخته است. از سوى ديخر بخشهايى از اين جنَــلهـــا

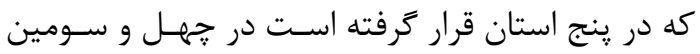
اجلاس كميته ميراث جهانى يونسكو •1 جولاى (9 تير ماه 19 1) به عنوان ذخيرهاه طبيعى زيست

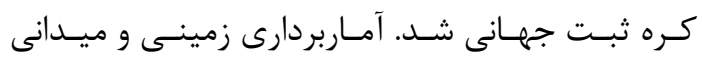

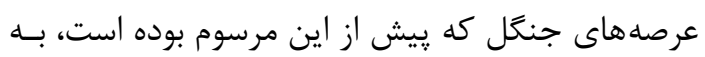

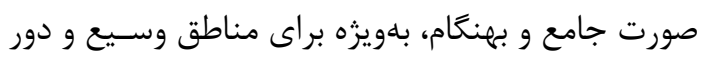

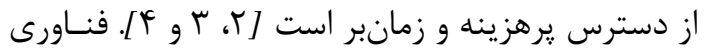

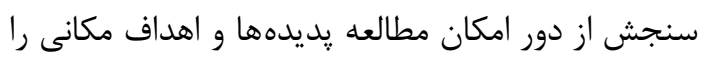

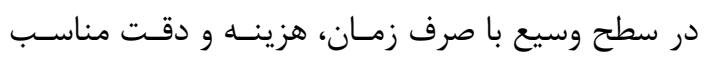
فراهم ساخته است.

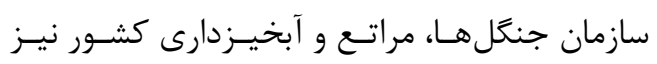

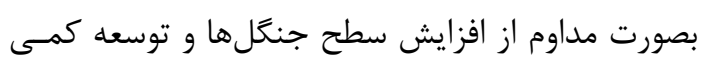

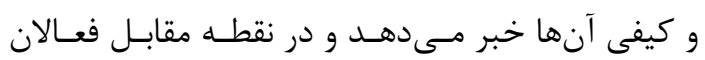

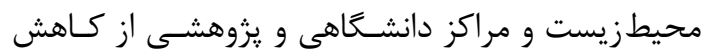

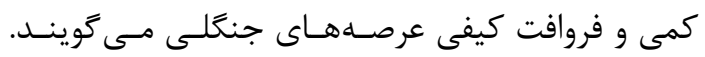

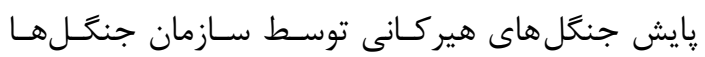
عمدتا" بر روشهــاى تفسـير بصـرى اسـتوار بـوده و در

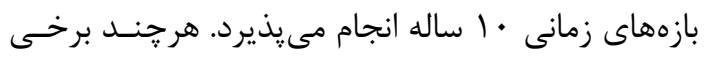

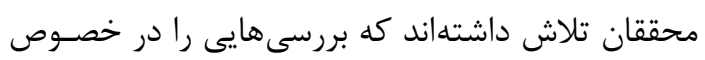

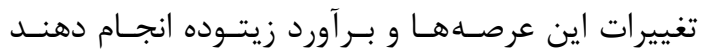
وليكن اين مطالعات عمدتا" مقطعى بوده و روند منظمه و

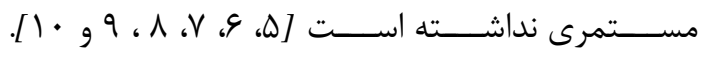

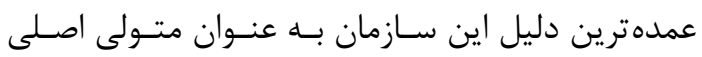


كلستان مشخص شد.

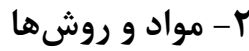

در ايـن بخـش منطقــه مطالعـاتى، دادههــاى مـورد

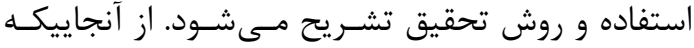
هدف اصلى اين تحقيق بهبود مدل FCD مىباشد، ابتدا

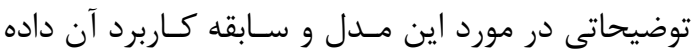
شده است و در ادامه بهبود ايجاد شده بــراى ايسن مــدل بيان مىشود.

r-1 - منطقه مطالعاتى

منطقه مطالعاتى جنگل هاى هير كانى مناطق شمال

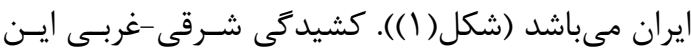
جنگل ها شرايط متفــاوت دمـايى و اتمسـفرى را باعـث

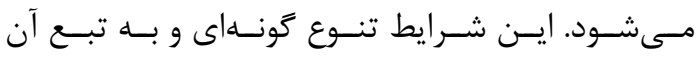

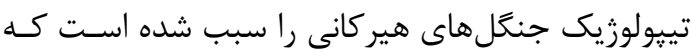
خود جالشى جديد براى مدل FCD است.

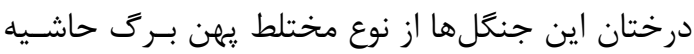

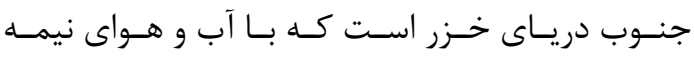
مديترانهاى و مرطوب سازگارند. معروفترين گَونههـا در

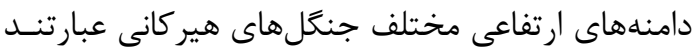

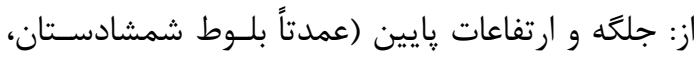

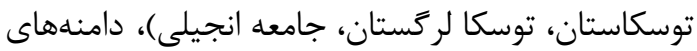

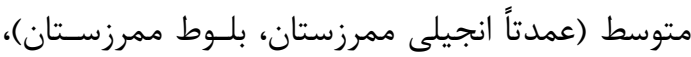

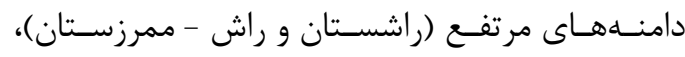

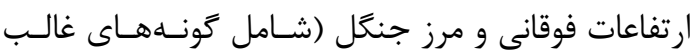
اورى، لور، سرو سابينا و كامونيس). r-r - داده مورد استفاده

دشوارى دسترسى به داده و هزينه آن همواره يكى

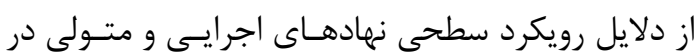

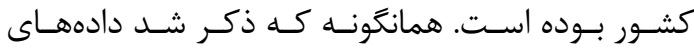
ماهوراهاى همجون لندست، سـنتينل، مـاديس و ديخـر

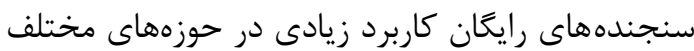
ســنش ازدور دارنــد. بــه همـين دليـل نيـز از تصــاوير

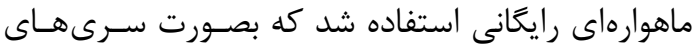
منظم زمانى قابل دسـترس باشـد. از ايسن روى تصـاوير

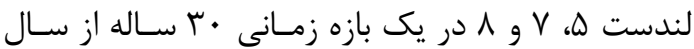

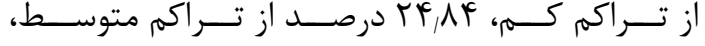
r, זr,

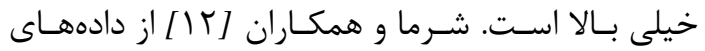
سنجنده LISS-4 براى ارزيابى تراكم جنگل هاى منطقـهـ

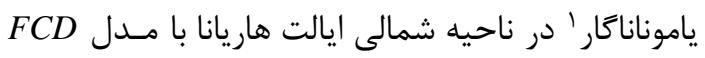

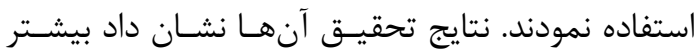

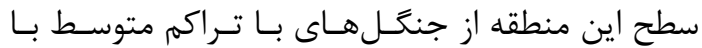

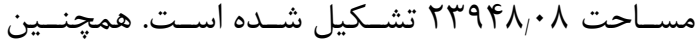

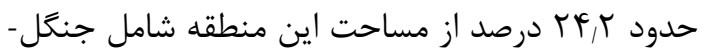
هاى باز است كه نياز به برنامهريزى براى افزايش تـراكم

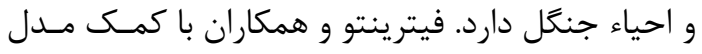
FCD

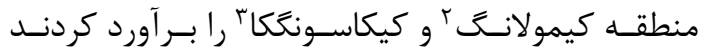
[11][. شاهولى كوهشور و همكاران از مدل تراكم تاج-

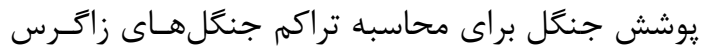

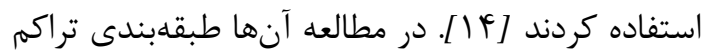

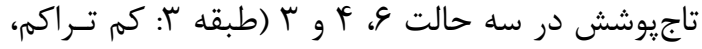
طبقه \&ٔ: تراكم متوسط و طبقه و: با تراكم زيـاد) طبقـهـ

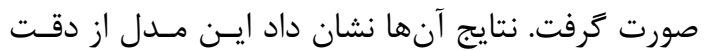
كافى براى يايش جنگل هاى زاگرس برخوردار است. يكى از جـالشهــاى اصـلى مـدل FCD ضـعف در

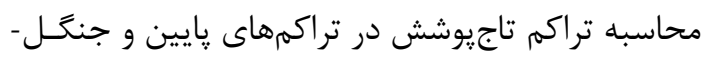

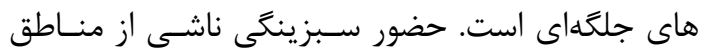

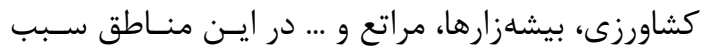

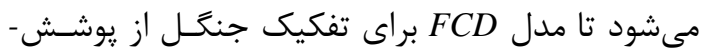

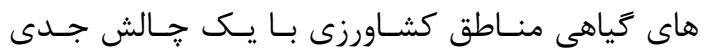
مواجه شود. بـهـ منظــور كـاهش اثـرات ايـن جــالش دو مرحله به مدل FCD اوليه اضافه شد. يرادهسازى مـدل

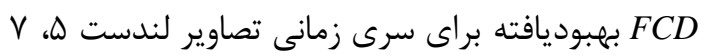

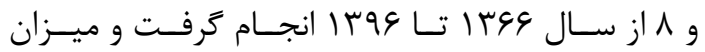
تغييـرات بـه تفكيـك سـه اسـتان خـيلان، مازنـدران و

${ }^{1}$ Yamunanagar

${ }^{2}$ Cimulang

${ }^{3}$ Cikasungka 
در نهايت يس از جستجوى بسيار و بررسى صدها فـريم تصويرى، تصاوير مندرج در جدول( (1) استفاده شد. بطور متوسط براى هر زمان 9 تصوير انتخاب شد كه مجموعا

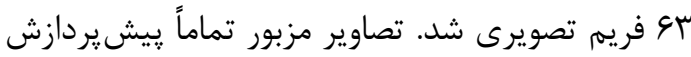

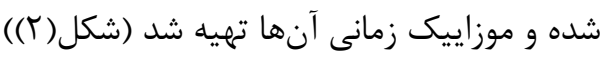

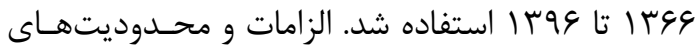
مربوط به انتخاب داده عبارت بود از: همزمانى نسبى: تصاوير بايد بين تير ماه تـا مهر مـاه

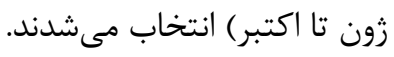
- سبزينكى حداكثر

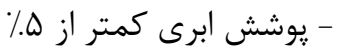

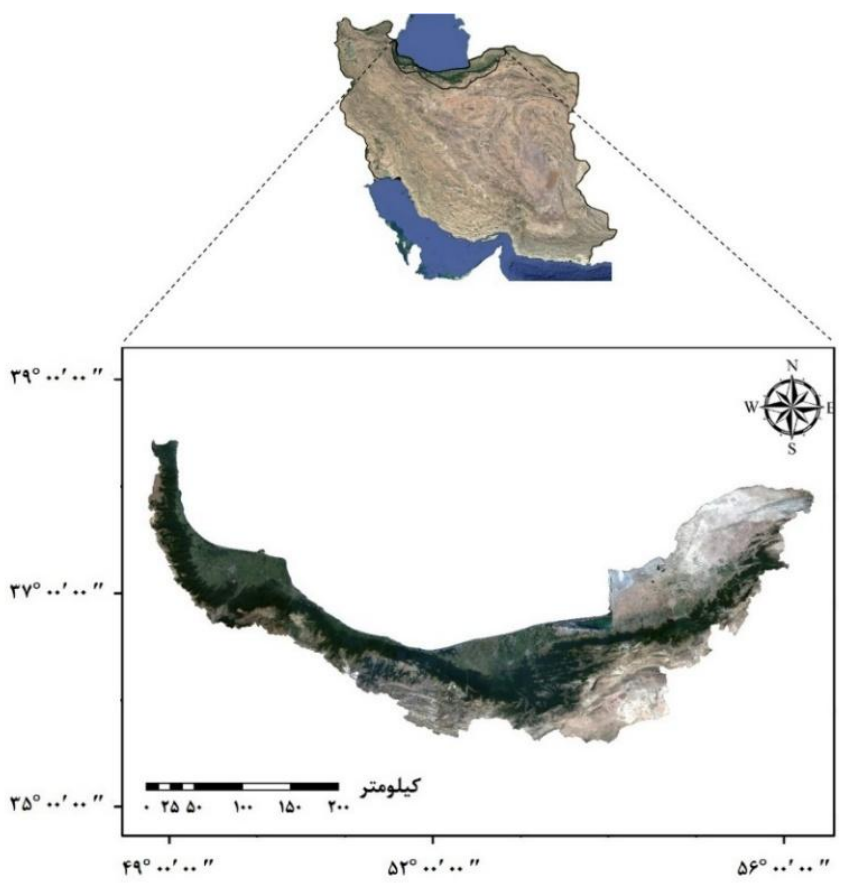

شكل ا: جنكل هاى ناحيه رويشى هير كانى به عنوان محدوده مورد مطالعه

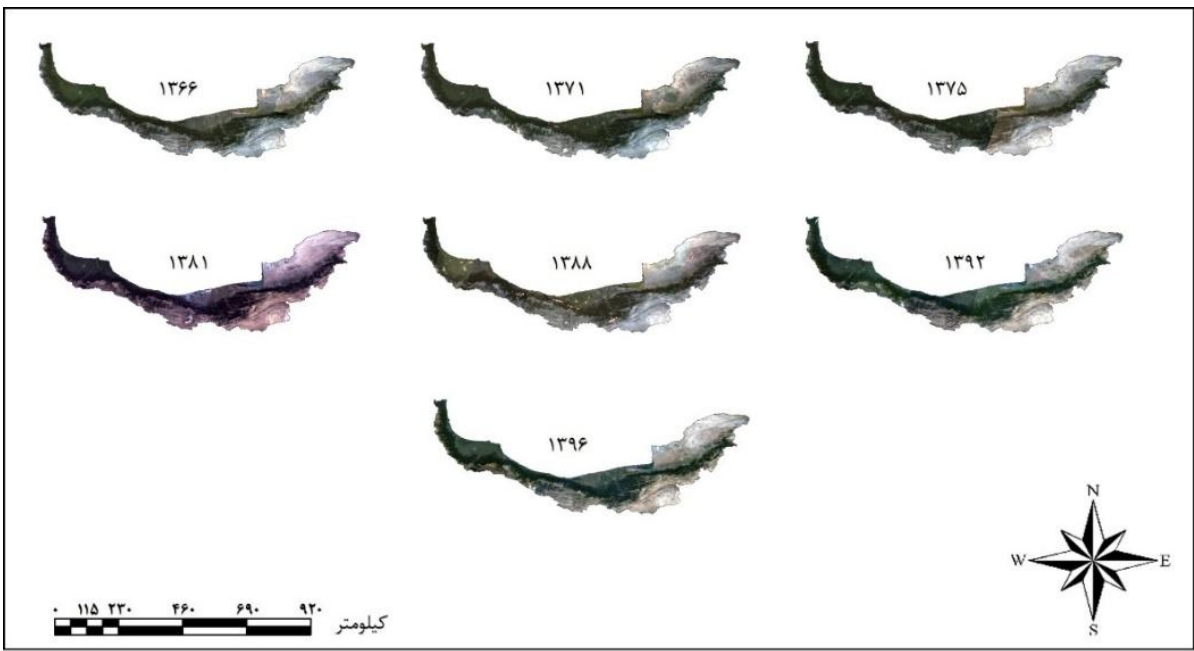

شكل r: تصاوير بيش يردازش شده از جنكَلهاى هير كانى در بازههاى زمانى مختلف 
معرفـى مـدل بهينـه شـده FCD بــه منظــور ارزيـابى و .

مسعود طايفى فيجانى و سعيد آز ادنزاد

جدول ا: تصاوير ماهوارهاى بازه زمانى سىساله بررسى تغييرات تراكمى جنغل هاى هير كانى

\begin{tabular}{|c|c|c|c|c|c|c|c|c|c|}
\hline ماهواره & تاريخ ميلادى تصوير & رديف & مسير & لـازه زمانى & ماهواره & تاريخ ميلادى تصوير & رديف & مسير & بازه زمانى \\
\hline لندسته & $\cdot q-1 \cdot-r \cdot \cdot q$ & m & 194 & \multirow{9}{*}{ ينجم } & ل لندسته & $1 \cdot-\cdot \wedge-19 \wedge \mathrm{V}$ & re & 194 & \multirow{9}{*}{ اول } \\
\hline ل لندسته & $r r_{-} \cdot \Lambda-r \cdot \cdot q$ & rd & 194 & & ل لندست ه & $1 \cdot-\cdot \wedge-19 \wedge \vee$ & ra & Ist & \\
\hline ل لندسته & $r q-\cdot q-r \cdot \cdot q$ & m & س & & لندسته & $19-\cdot V-191 V$ & re & سوו & \\
\hline لندسته & $r \Lambda_{-} \cdot V_{-} r \cdot \cdot q$ & ra & س & & ل لندسته & $1 F_{-} \cdot \Lambda_{-} 19 \wedge v$ & ra & س & \\
\hline ل لندسته & $19-\cdot V-r \cdot \cdot 9$ & $r \Delta$ & 194 & & ل لندسته & $r r_{-} \cdot V_{-} 19 \wedge V$ & rd & ISF & \\
\hline لندسته & $1 r_{-} \cdot q-r \cdot . q$ & ry & 190 & & لندست ه & $19_{-} \cdot 9-191 \mathrm{~V}$ & ry & 190 & \\
\hline لندسته & $\mid r_{-} \cdot q-r_{\cdot} \cdot q$ & ra & 190 & & لندسته & $19-.9-191 \mathrm{~V}$ & rd & 190 & \\
\hline لندسته & $\cdot 1-\cdot V-r \cdot \cdot 9$ & my & 199 & & لندسته & $\cdot \Delta_{-} \cdot V_{-} 19 \wedge \mathrm{V}$ & re & 199 & \\
\hline لندسته & $r q_{-} \cdot q_{-} r \cdot \cdot q$ & س & $19 \mathrm{~V}$ & & ل لندسته & $r \Lambda_{-} \cdot V_{-} 19 \wedge \mathrm{V}$ & س & $19 V$ & \\
\hline ل لندسته & $19-\cdot V-r \cdot 1 r$ & m & 194 & \multirow{9}{*}{ مشم } & لندست ه & $\cdot 1_{-} \cdot 9-1994$ & ry & Ist & \multirow{9}{*}{ 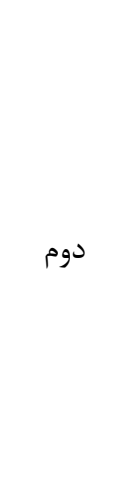 } \\
\hline لندسته & $\left|V_{-} \cdot \Lambda-r \cdot\right| r$ & ra & 195 & & لندسته & $\cdot \Lambda_{-} \cdot 9-199 r$ & rd & IST & \\
\hline لندسته & $r r_{-} \cdot \Lambda_{-} r \cdot \mid r$ & m & س & & لندست ه & $1 F_{-} \cdot \Lambda_{-} 1994$ & re & سوו & \\
\hline لندسته & $\cdot V_{-} \cdot V_{-} r \cdot I r$ & ra & س & & لندسته & $\cdot V_{-} \cdot 9-199 r$ & rd & سوו & \\
\hline لندسته & $\mid \Lambda-1 \cdot-r \cdot 1 r$ & ra & lgF & & لندست ه & $.9-.9-199 r$ & $r \Delta$ & lat & \\
\hline لندسته & $19-\cdot q_{-r} \cdot 1 r$ & ry & 190 & & لندسته & $r r-.9-199 r$ & ry & 190 & \\
\hline لندسته & $19_{-} \cdot q_{-r} \cdot 1 r$ & ra & 190 & & لندسته & $r \Lambda_{-} \cdot 9-199 r$ & $r \Delta$ & 190 & \\
\hline لندسته & $\mid 9-1 \cdot-r \cdot 1 r$ & mF & 199 & & لندسته & $19-\cdot 1-1994$ & re & 199 & \\
\hline لندسته & $1 V-\cdot 9-r \cdot 1 r$ & س & $19 \mathrm{~V}$ & & لندسته & r9-・1-199r & س & $19 V$ & \\
\hline لندست & $r \Lambda_{-} \cdot \Lambda_{-} r \cdot I V$ & ru & 195 & \multirow{9}{*}{ هفتم } & لندست ه & $\cdot r_{-} \cdot 9-1999$ & re & 195 & \multirow{9}{*}{ سوم } \\
\hline لندست & $r \Delta_{-} \cdot \varphi_{-} r \cdot 1 V$ & ra & 195 & & لندسته & $\cdot r_{-} \cdot q_{-} 1999$ & $r d$ & IGT & \\
\hline لندست & $1 \Lambda_{-} \cdot V_{-} r \cdot \mid V$ & mi & 19 & & لندسته & $r \Delta_{-} \cdot \Lambda_{-} 1999$ & m & 194 & \\
\hline لندست & $1 \Lambda_{-} \cdot V_{-} r \cdot I V$ & rd & 19 & & لندست ه & $r \Delta_{-} \cdot \Lambda_{-} 1994$ & $r \Delta$ & سوו & \\
\hline لندست1 & $1 \cdot-\cdot \Lambda-r \cdot I V$ & ra & laf & & لندست ه & $\cdot 1-\cdot 9-1999$ & $r d$ & lat & \\
\hline لندست & $\cdot r_{-} \cdot 9-r \cdot 1 V$ & m & 190 & & لندست ه & $r r-\cdot{ }_{-1999}$ & re & 190 & \\
\hline لندست & $r \cdot-\cdot 9-r \cdot 1 V$ & ra & 190 & & لندسته & $\cdot 1_{-} \cdot 9-1999$ & rd & 190 & \\
\hline لندست & $\cdot \Lambda_{-} \cdot \Lambda_{-} r \cdot I V$ & mF & 199 & & لندسته & $r_{-} \cdot v_{-} 1999$ & mp & 199 & \\
\hline \multirow[t]{10}{*}{ لندست1 } & $\left|\Delta_{-} \cdot \Lambda_{-} r \cdot\right| \nabla$ & س & $19 \mathrm{~V}$ & & لندسته & $\cdot \Delta_{-} \cdot \Lambda_{-} 1999$ & س & $19 V$ & \\
\hline & & & & & لندست V & $1 \cdot-\cdot V-r \cdot r$ & re & IET & \multirow{9}{*}{ جهارم } \\
\hline & & & & & لندست V & $1 \cdot-\cdot V-r \cdot r$ & rd & IET & \\
\hline & & & & & لندستV & $I V-\cdot V-r \cdot r$ & me & 194 & \\
\hline & & & & & لندست V & $I V_{-} \cdot V_{-} r \cdot r$ & ra & س & \\
\hline & & & & & VلندستV & $\cdot q_{-} \cdot \Lambda_{-} r \cdot \cdot r$ & rd & lat & \\
\hline & & & & & لندستV & $r ו-v-r \cdot r$ & ry & 190 & \\
\hline & & & & & لندست V & $r 1-\cdot v-r \cdot r$ & rd & 190 & \\
\hline & & & & & لندست V & $\cdot V_{-} \cdot \Lambda_{-} r \cdot \cdot r$ & ry & 199 & \\
\hline & & & & & لندست V & $r q_{-} \cdot V_{-} r \cdot \cdot r$ & س & $19 V$ & \\
\hline
\end{tabular}




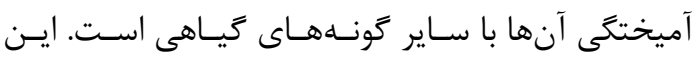
حساسـيت وجـهـ تمـايز تحقيقـات محققـان در منــاطق

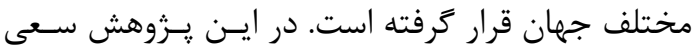
شد با تمركز روى اين نكات مدلى بـا بهتـرين عملكـرد براى مناطق جنكلى هير كانى توسعه و بهبود داده شود.

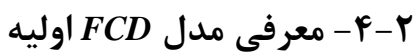

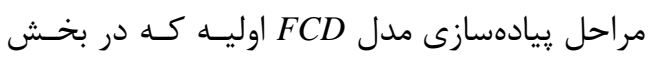

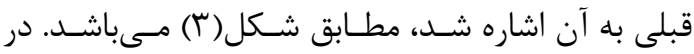
ادامه اين مراحل شرح داده شده است. r-r - مدل FCD و سابقه كاربرد آن

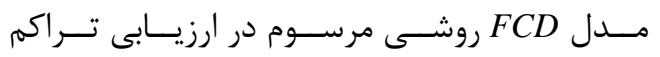

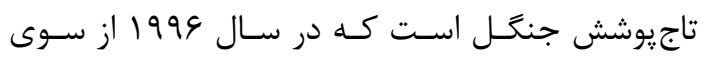

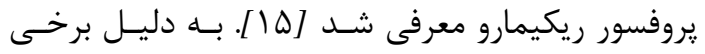

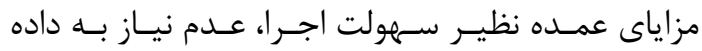

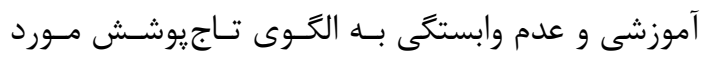

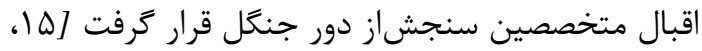

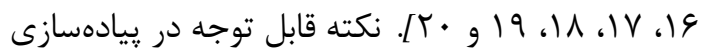

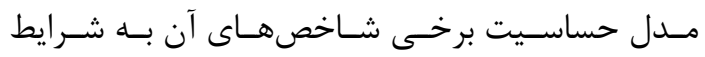
محيطى و يراكنش تيبهاى جنكلى و همجنين ميـزان

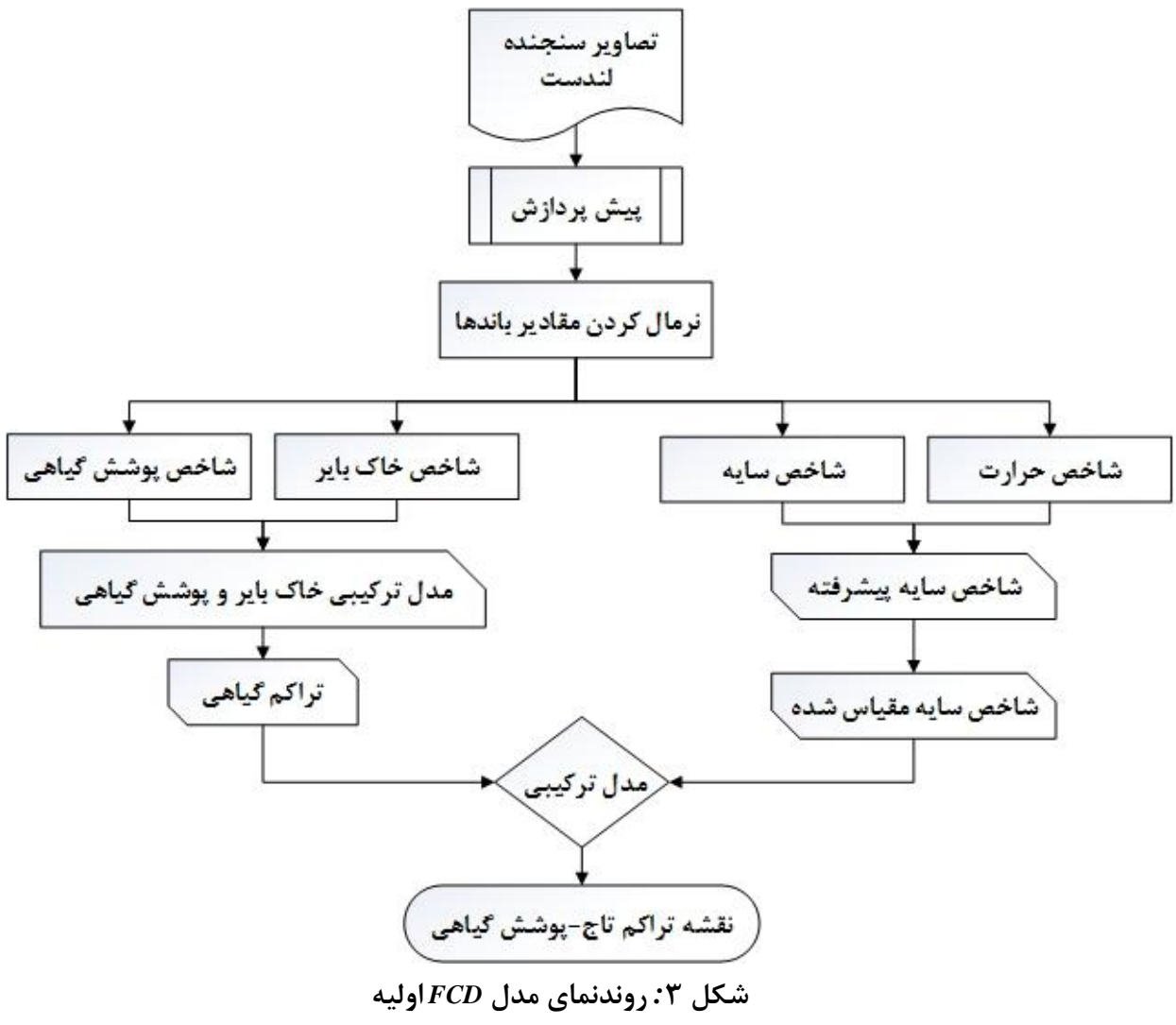

است. بنابراين، تمامى تصاوير قبل از وارد شدن بـهـ ايـن مدل بايد از لحاظ هندسى و راديومتريكى تصحيح شده

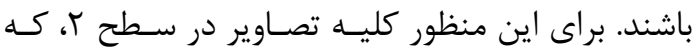
تصحيحات لازم بر روى آن انجام گرفته است، از يايخاه https://earthexplorer.usgs.gov
در مرحله اول يُيشيردازش و آمـادهسـازى تصـاوير شامل تصحيحات هندسى، تصحيحات راديـومتريكى و

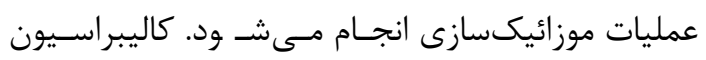

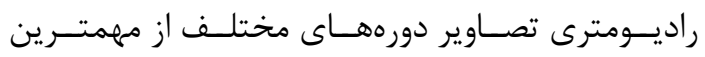
موضوعات در تحليـل سـرى زمـانى تصـاوير مـاهوارهاى 


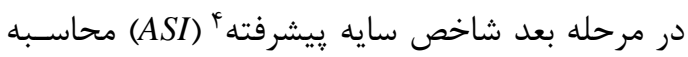
مىشود. در مدل FCD معمولى شاخص سايه رِيشـرفته با آستانه گذارى و تركيب سه شـاخص مس سـايه، گيـاهى و حرارت انجام مى گيرد. اين سه شاخص به تنهايى بـراى تفكيك يوشش درختـى از ديخـر ريوشـش هـاى گيـاهى

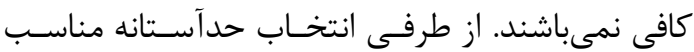

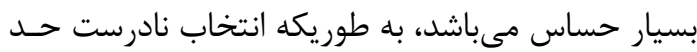

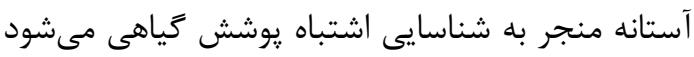

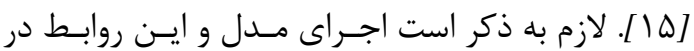

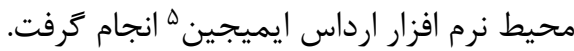

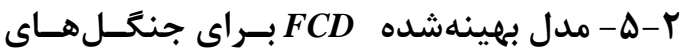

\section{بهنبرَ مختلط هير كانى}

در مناطق یايين دست و جلحهاى، لكههاى اندكى از

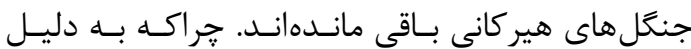

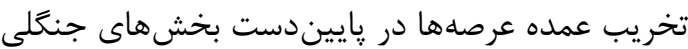

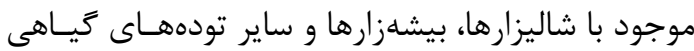

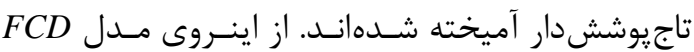
توانايى اندكى در متمايز كردن اين لكههاى محـدود بـاــا

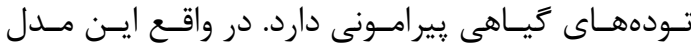

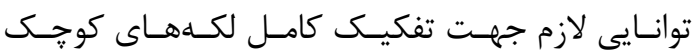
جنكَلى از مناطق كشاورزى، بوتـهـارهـا، بيشـهزارهــا و مناطق با بوشش كَياهى متراكم غيرجنَلى را ندارد. بــه منظور رفع اين جالش، طى دو مرحله زير عملكرد مدل در اين مناطق بهبود يافت: 1- تقويت شاخص سايه با استفاده از شاخص تركيسب

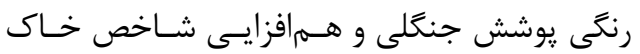
باير بـ آن r- استفاده از كرنل ميانگين

\footnotetext{
${ }^{4}$ Advanced Shadow Index
}

${ }^{5}$ ERDAS IMAGINE
هندسى و راديومتريك در تصاوير لندسـت سـطح ب بـهـ صورت سيستماتيك انجام مى گيرد. همجنين در اين مرحله كليه ويزگگى هاى مسـتخرج از تصوير، به استثناى شاخص حرارتى، مطابق رابطه(1)

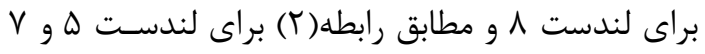

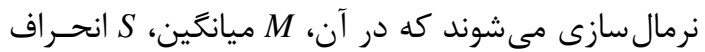
معيار دادهها، X مقادير عددى تصوير اوليه در هر بانـد و بالاخره Y مقادير عددى نرمال شده مىباشند. در مرحلـه بعد مقادير شاخصهاى خاى باير، سايه، حرارت، كياهى ييشرفته و يك شاخص جديد، كه به منظور بهبود مدل

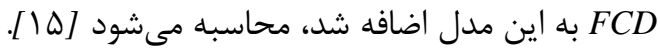
شاخص گياهى ريشرفته' (AVI) بر اساس مقـادير

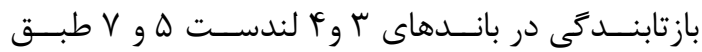

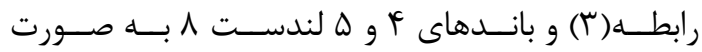

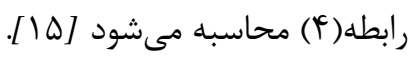

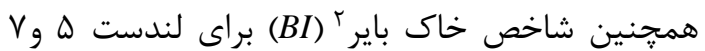
طبق رابطه(ه) و لندست 1 طبق رابطه( (9) بهدست مى آيد [ها $[0$.

شاخص حرارتץ (TI) شاخص حرارتى كه منبــع آن آن

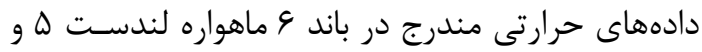
V و باند • ا لندست 1 مىباشد، براى لندست ه و ل بـر

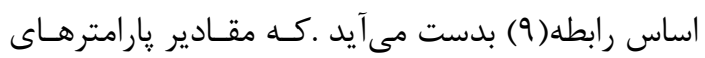

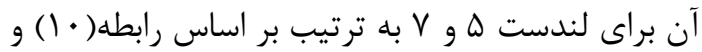

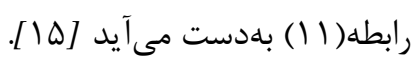

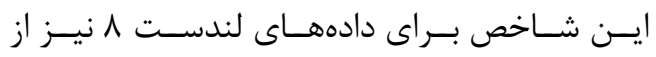

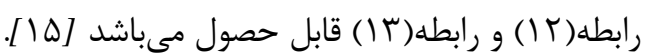

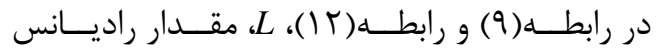
بركشتى در باند مادون قرمز حرارتـى، Q مقـدار عـددى

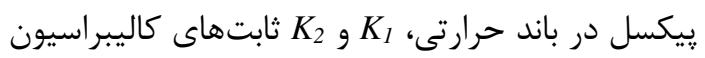

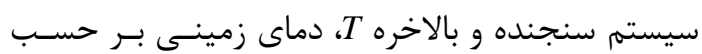

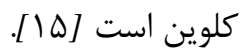

${ }^{1}$ Advanced Vegetation Index

${ }^{2}$ Bare soil Index

${ }^{3}$ Thermal Index 
$\mathrm{X}_{1}=\mathrm{M}-2 \mathrm{~S}, \mathrm{X}_{2}=\mathrm{M}+2 \mathrm{~S}$

$Y_{1}=20, Y_{2}=65520$

$A=\frac{Y_{1}-Y_{2}}{X_{1}-X_{2}}=\frac{20-65520}{(M-2 S)(M+2 S)}=\frac{16375}{S}$

(1) (1)

$\mathrm{B}=-\mathrm{AX}_{1}+\mathrm{Y}_{1}$

$\mathrm{Y}=\mathrm{AX}+\mathrm{B}$

$\mathrm{X}_{1}=\mathrm{M}-2 \mathrm{~S}, \mathrm{X}_{2}=\mathrm{M}+2 \mathrm{~S}$

$\mathrm{Y}_{1}=20, \mathrm{Y}_{2}=220$

$A=\frac{Y_{1}-Y_{2}}{X_{1}-X_{2}}=\frac{20-220}{(M-2 S)(M+2 S)}=\frac{50}{S}$

(T) رابطه (r)

$\mathrm{B}=-\mathrm{AX}_{1}+\mathrm{Y}_{1}$

$\mathrm{Y}=\mathrm{AX}+\mathrm{B}$

$\mathrm{B} 4-\mathrm{B} 3<0 \Rightarrow \mathrm{AVI}=0$

$\mathrm{B} 4-\mathrm{B} 3>0 \Rightarrow \mathrm{AVI}=[(\mathrm{B} 4+1)(256-\mathrm{B} 3)(\mathrm{B} 4-\mathrm{B} 3)]^{(1 / 3)}$

(ب) رابطه()

$\mathrm{B} 5-\mathrm{B} 4<0 \Rightarrow \mathrm{AVI}=0$

$\mathrm{B} 5-\mathrm{B} 4>0 \Rightarrow \mathrm{AVI}=[(\mathrm{B} 5+1)(65536-\mathrm{B} 4)(\mathrm{B} 5-\mathrm{B} 4)]^{(1 / 3)}$

(ابطه)

$\mathrm{BI}=\frac{(\mathrm{B} 5+\mathrm{B} 3)-(\mathrm{B} 4+\mathrm{B} 1)}{(\mathrm{B} 5+\mathrm{B} 3)+(\mathrm{B} 4+\mathrm{B} 1)} \times 100+100$

(ه) (ه)

$\mathrm{BI}=\frac{(\mathrm{B} 6+\mathrm{B} 4)-(\mathrm{B} 5+\mathrm{B} 2)}{(\mathrm{B} 6+\mathrm{B} 4)+(\mathrm{B} 5+\mathrm{B} 2)} \times 100+100$

(9) رابطه

$\mathrm{SI}=[(256-\mathrm{B} 1)(256-\mathrm{B} 2)(256-\mathrm{B} 3)]^{(1 / 3)}$

(V) رابطه

$\mathrm{SI}=[(65536-\mathrm{B} 2)(65536-\mathrm{B} 3)(65536-\mathrm{B} 4)]^{(1 / 3)}$

(1) (1)

$\mathrm{L}=\mathrm{L}_{\text {min }}+\left(\frac{\mathrm{L}_{\text {max }}-\mathrm{L}_{\min }}{255}\right) \times \mathrm{Q}, \quad \mathrm{T}=\frac{\mathrm{K}_{2}}{\operatorname{Ln}\left(\frac{\mathrm{K}_{1}}{\mathrm{~L}}+1\right)}$

(9) (9) 
$\mathrm{K}_{1}=607.76 \frac{\text { watts }}{\left(\mathrm{m}^{2} \times \text { ster } \times \mu \mathrm{m}\right)}$

$\mathrm{K}_{2}=1260.56$ (kelvin)

Lmin $=1.238 \frac{\text { watts }}{\left(\mathrm{m}^{2} \times \text { ster } \times \mu \mathrm{m}\right)}$

$\operatorname{Lmax}=15.303 \frac{\text { watts }}{\left(\mathrm{m}^{2} \times \text { ster } \times \mu \mathrm{m}\right)}$

$\mathrm{K}_{1}=666.09 \frac{\text { watts }}{\left(\mathrm{m}^{2} \times \text { ster } \times \mu \mathrm{m}\right)}$

$\mathrm{K}_{2}=1282.71$ (kelvin)

Lmin $=0.000 \frac{\text { watts }}{\left(\mathrm{m}^{2} \times \text { ster } \times \mu \mathrm{m}\right)}$

$\operatorname{Lmax}=17.040 \frac{\text { watts }}{\left(\mathrm{m}^{2} \times \text { ster } \times \mu \mathrm{m}\right)}$

$\mathrm{L}=\mathrm{L}_{\text {min }}+\left(\frac{\mathrm{L}_{\text {max }}-\mathrm{L}_{\min }}{65536}\right) \times \mathrm{Q}, \quad \mathrm{T}=\frac{\mathrm{K}_{2}}{\operatorname{Ln}\left(\frac{\mathrm{K}_{1}}{\mathrm{~L}}+1\right)}$

$\mathrm{K}_{1}=774.8853 \frac{\text { watts }}{\left(\mathrm{m}^{2} \times \text { ster } \times \mu \mathrm{m}\right)}$

$\mathrm{K}_{2}=1321.0789$ (kelvin)

Lmin $=0.10033 \frac{\text { watts }}{\left(\mathrm{m}^{2} \times \text { ster } \times \mu \mathrm{m}\right)}$

Lmax $=22.00180 \frac{\text { watts }}{\left(\mathrm{m}^{2} \times \text { ster } \times \mu \mathrm{m}\right)}$

سايه ريشرفته بوده و مقادير آن از صفر تـا صـد مرتـب شده است بلهست مى آيد. در مرحله بعد شاخص تـراكم كياهى ب (VD) محاسبه مى شود. اين شاخص مؤلفــه اول

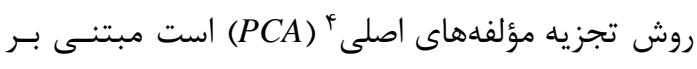

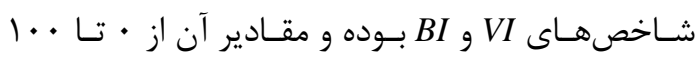

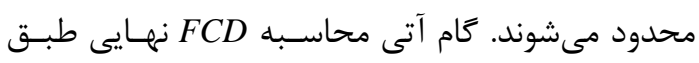

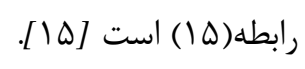

${ }^{3}$ Vegetation Density

${ }^{4}$ Principal Component Analysis
رابطه( •)

رابطه(1)

رابطه(1) (1) (1)

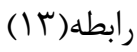
r-1-1- تقويت شاخص سايه

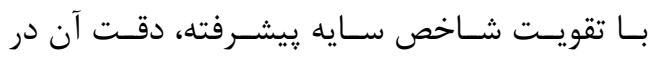
تفكيك يوشش درختى از يوشش كيـاهى غيـر درختى

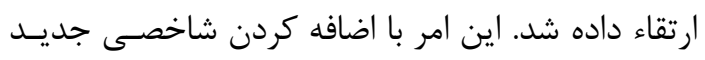
به نام تركيب رنكى يوشش جنگل و همجنــين شـاخص خاك باير صورت كرفت. شاخص جديد تركيب رنتى جنگل ' (FCCI) است

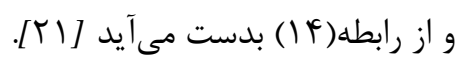

يس از محاسبه شـاخص سـايه يِيشـرفته، شـاخص

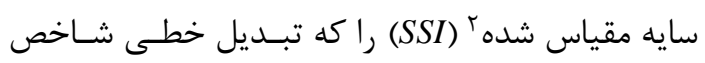

${ }^{1}$ Forest Color Composite Index

${ }^{2}$ Scaled Shadow Index 
$\left\{\begin{array}{l}\text { Red }(\mathrm{R})=\text { SWIR } \\ \text { Green }(\mathrm{G})=\text { NDVI } \\ \text { Blue }(\mathrm{B})=\text { Green }\end{array} \Rightarrow\right.$ FCCI $=\frac{\text { SWIR }+ \text { NDVI }+ \text { Green }}{3}$

$\mathrm{FCD}=\sqrt{\mathrm{VD} \times \mathrm{SSI}+1}-1$

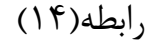

رابطه(ه) (1ه)

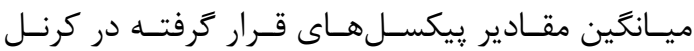

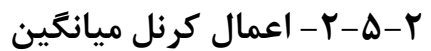

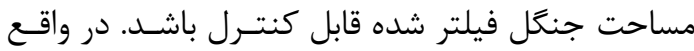

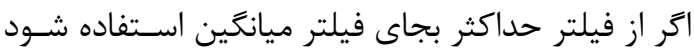

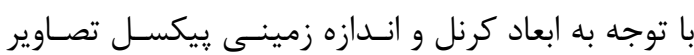
لندست فقط جنكل هاى بـا مسـاحت بـيش از \& هكتـار

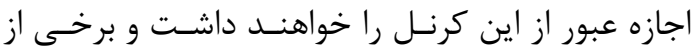

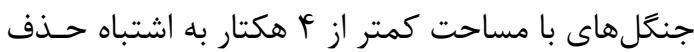

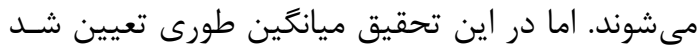

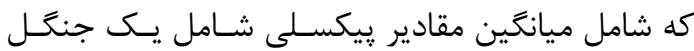

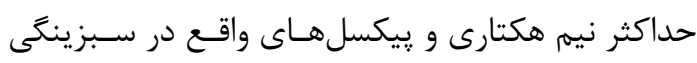

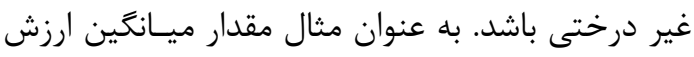
ييكسلى نقشه تـراكم تـاج-يوشـش يـك مجموعـانه

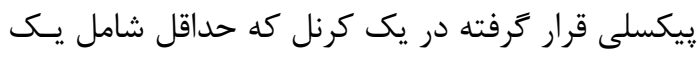

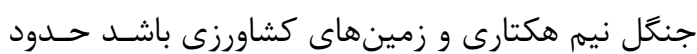

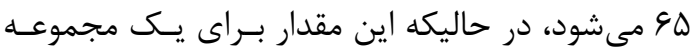
يريكسل كه همكى شامل زمين كشـاورزى باشــند برابـر

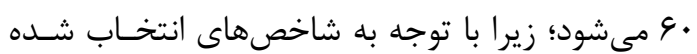
در اين مدل سبزينكى جنكل مقادير بيكسلى بيشـترى

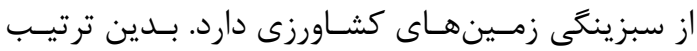

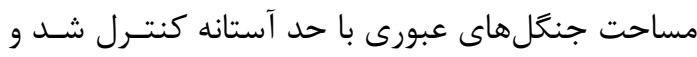
جنكَلهاى حذف شده مغايرتى با تعريف جهانى جنَــل

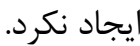

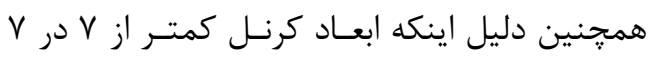

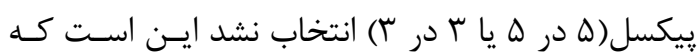
ابعاد كمتر از اين مقدار ضمن افزايش زمـان محاسـبات،

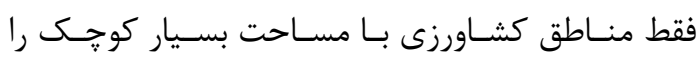

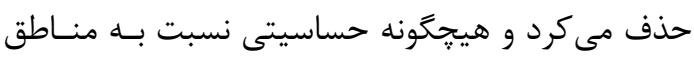

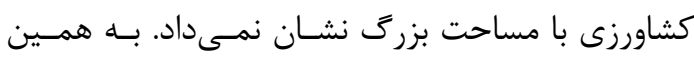

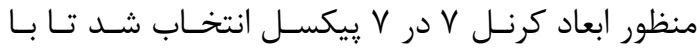

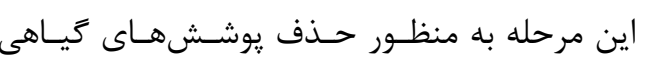
غيرجنَلى است كـهـ در منـاطق همــار و در ارتفاعـات

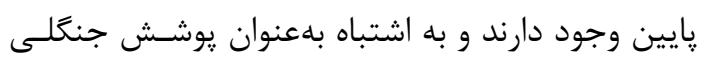

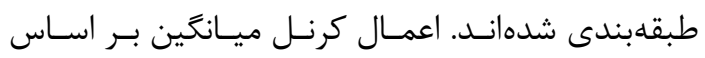

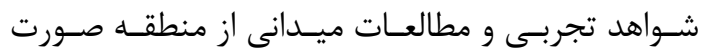

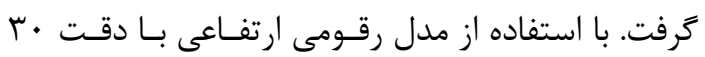

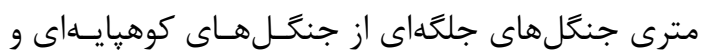

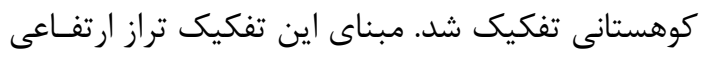

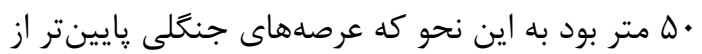

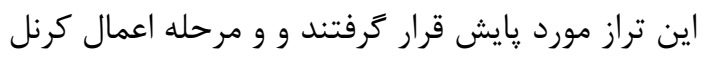
تنها بر روى اين مناطق انجام شد.

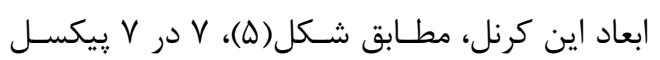

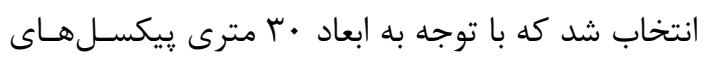

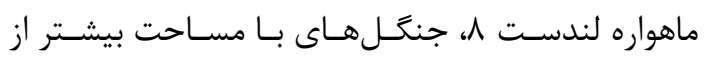

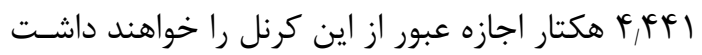

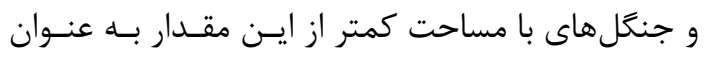

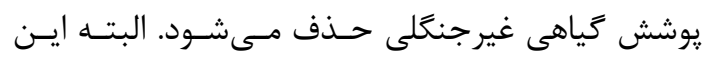

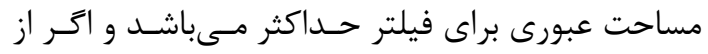

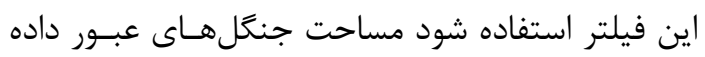

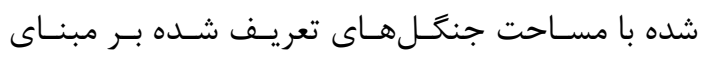

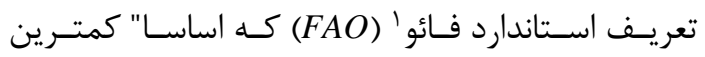

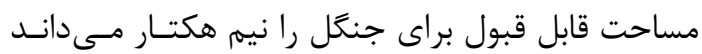

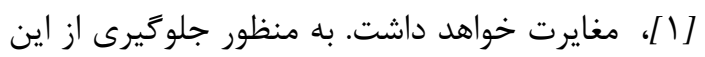

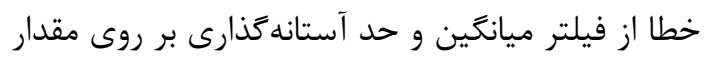

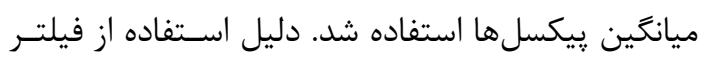

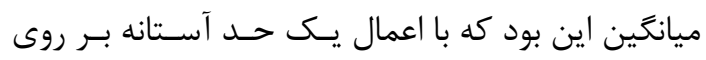

${ }^{I}$ Food and Agriculture Organization 


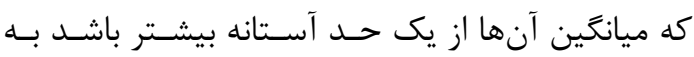

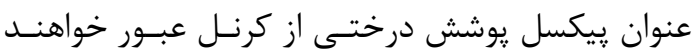
كرد و در غير اينصورت از نتايج مدل حذف خواهند آند شرل

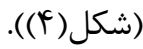

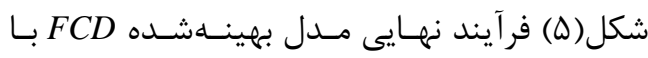

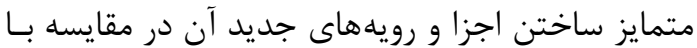
مدل ساده قديمى را نشان مى مدهد.
تعريف حد آسـتانه مناسـب زمسين هـاى كشـاورزى بـا

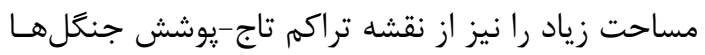

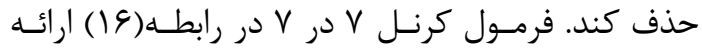
شده است. $\mathrm{I}(\mathrm{r}, \mathrm{c})=\frac{1}{49} \sum_{\mathrm{j}=-3 \mathrm{i}=-3}^{3} \sum^{3} \mathrm{I}(\mathrm{r}+\mathrm{i}, \mathrm{c}+\mathrm{j}) \quad$ (ابطه( ) كه در آن r شماره سطر بيكسل و c شـماره سـتون

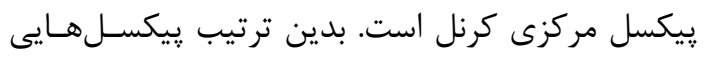
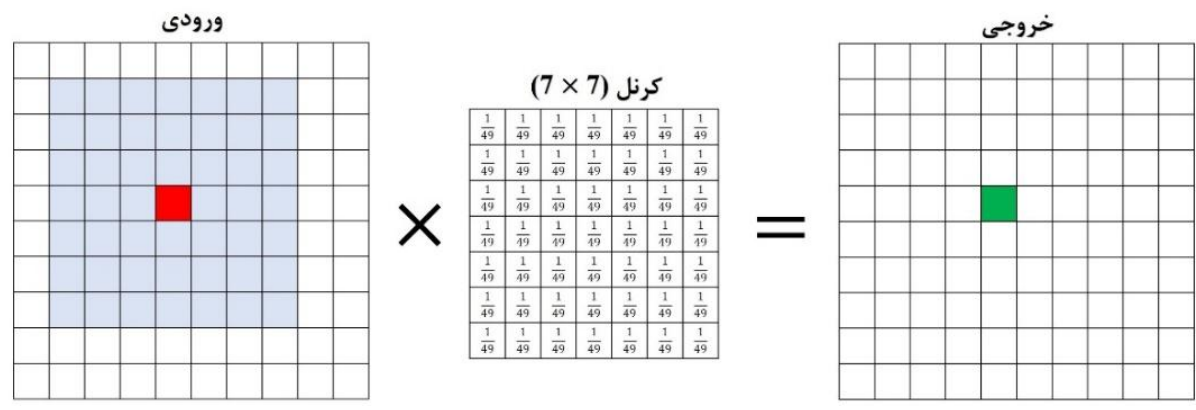

شكل †: نحوه اعمال كرنل ميانكين روى تصاوير

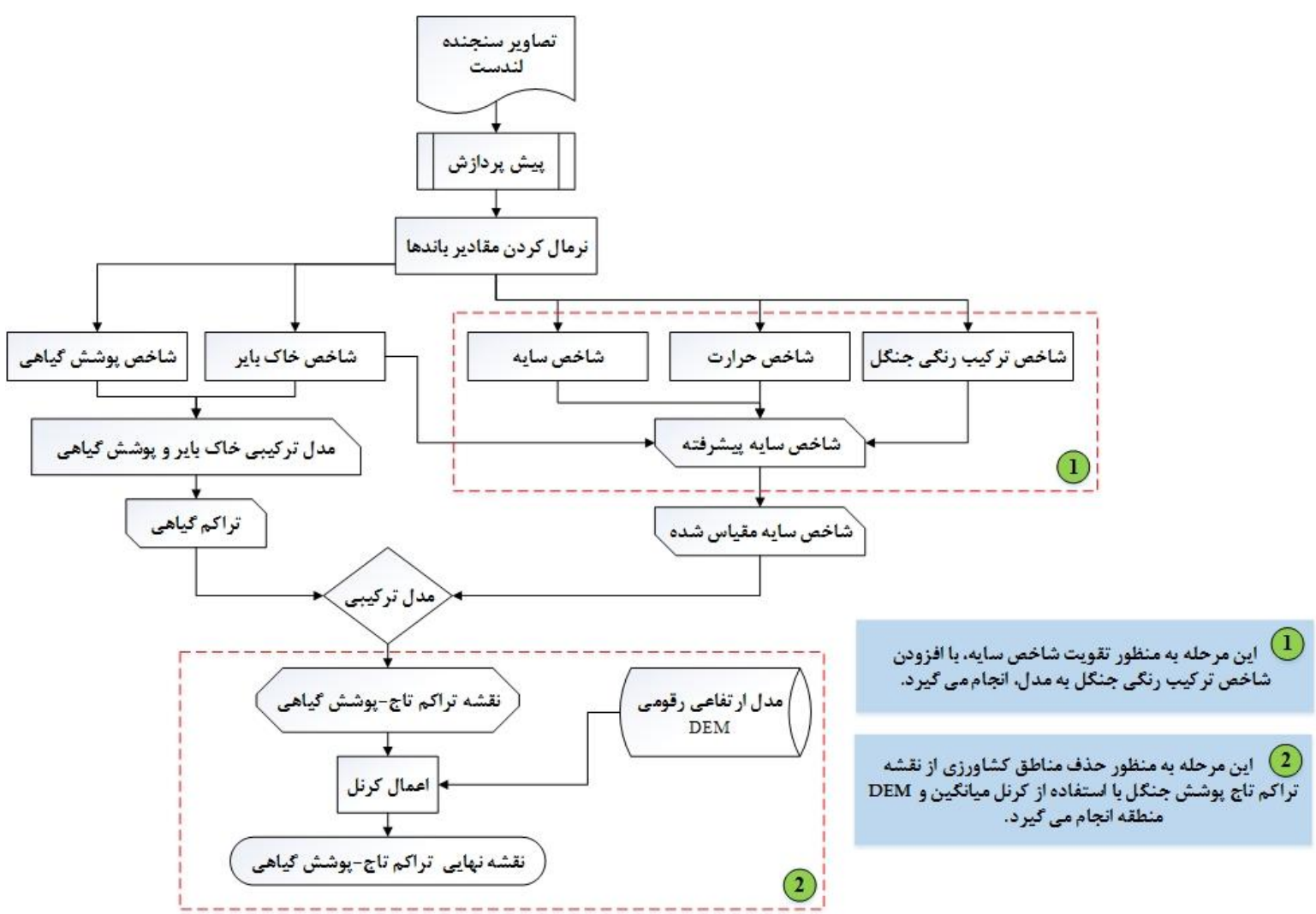

شكل ه: روندنماى مراحل بيادهسازى مدل بهينهشده FCD 
آمارهاى اعلامى سازمان جنكل ها مساحت جنحـلـهـاى

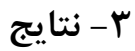
ايران از 1/1/ ميليون هكتار (بر مبناى •ا الدرصـد تـاج قبل از ارايه نتايج مطالعه، ضرورى است بـه تفـاوتى

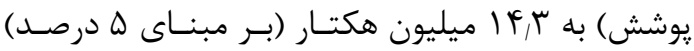

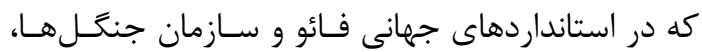

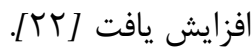

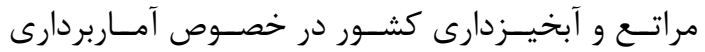
ץ-1- بررسى نتايج تغييرات مساحت جنَّلهـاى مناطق جنكلى وجود دارد اشاره شود. همانكَونه كه ذكر آركار

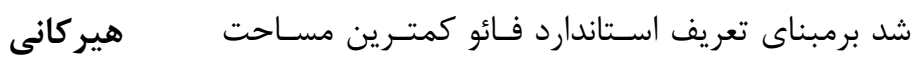

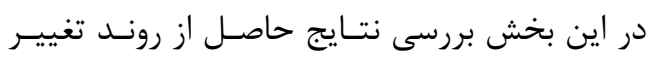
جنكل را نيم هكتار با حداقل تاج يوشـش كمتـر از لـ

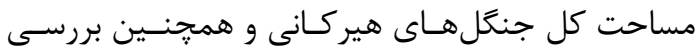
درصد مىباشد و اخـر مسـاحت يوششى تـاج درختان آنسان

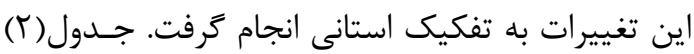

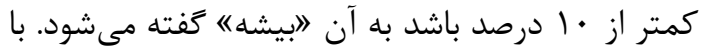

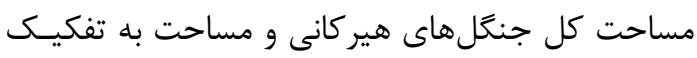

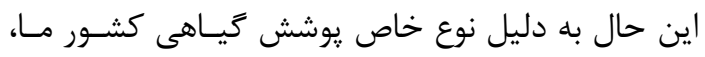
استان هاى كيلان، مازندران و كَلستان را براى سالهـاي

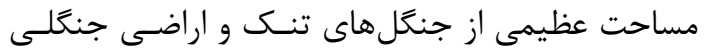
مختلف نشان مى دهد.

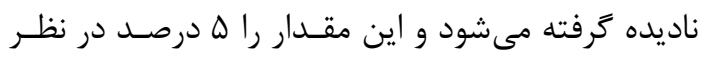

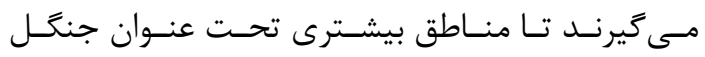
محافظت شود. بر اساس اين مغايرت در تعريف و طبـق بق بـ

جدول ץ: مساحت جنغَل هاى هير كانى به تفكيك استانهاى َيلان، مازندران و كلستان

\begin{tabular}{|c|c|c|c|c|}
\hline كَلستان & مازندران & كَيلان & مساحت كل (هكتار) & سال \\
\hline lఎq/बr,rVG & $F \vee \mathcal{F} / \mathcal{}(1, \wedge q$. & $\Lambda \cdot \Lambda / 19, \Delta F \wedge$ & $T / Y T, \Delta F T,|\wedge|$ & Ir49 \\
\hline$\wedge \wedge १ / q \cdot, r \vee \mathcal{F}$ & 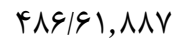 & $१ \Delta \Delta / \varsigma q, \Delta F \varnothing$ & $F / r), q(1, \mid \wedge$. & $|r v|$ \\
\hline 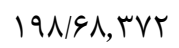 & $.9 \vee / \vee \Delta, \wedge \wedge 1$ & . $r q / T q, \Delta F r$ & $\Delta / 9 q, q$ r , IVq & IrVD \\
\hline$V \varepsilon \Psi|\varepsilon \Lambda, F|$. & $\Delta r V / \Delta \varphi, q V T$ & $. G F / M T, G \cdot 1$ & $\Delta / \Delta \Delta, \& \leftarrow \varepsilon, 19 \Lambda$ & $|r \wedge|$ \\
\hline rVG/TV,FII & I $19 / 9 r, q \vee F$ & $V G T / I F, G \cdot I$ & $\Delta / F I, V r r, 19 \Lambda$ & IrNA \\
\hline $91 \cdot / 9 V, r \cdot 1$ & 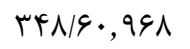 & $\mid \Delta \Delta / \vee q, \Delta ৭ \wedge$ & ه/F, & Irar \\
\hline$V T G / V I, Y \cdot V$ & $\Delta F F / \|, q \varphi \Delta$ & FTr/FI, ఎqG & F/rr,৭६৭, ।৭६ & Irq9 \\
\hline
\end{tabular}

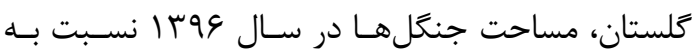

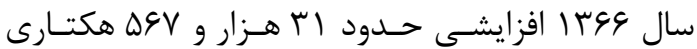

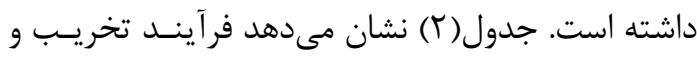

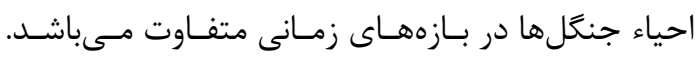

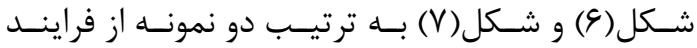

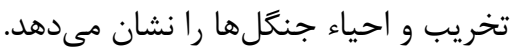

مطابق جدول(Y)، مساحت كل جنگل هاى هير كانى

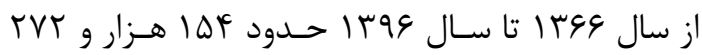
هكتار افزايش سطح داشـته اسـت. مسـاحت در حوضـهـ آنسال

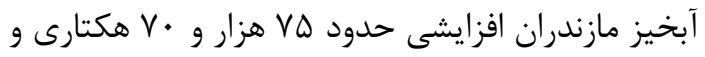

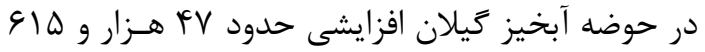
هكتارى داشته است. همجزنين در مـورد حوضـهـ آبخيـز 
(a)

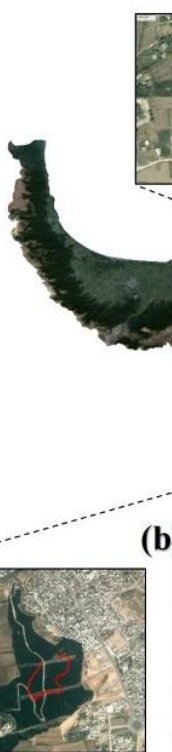

$|r \wedge|$

(b)
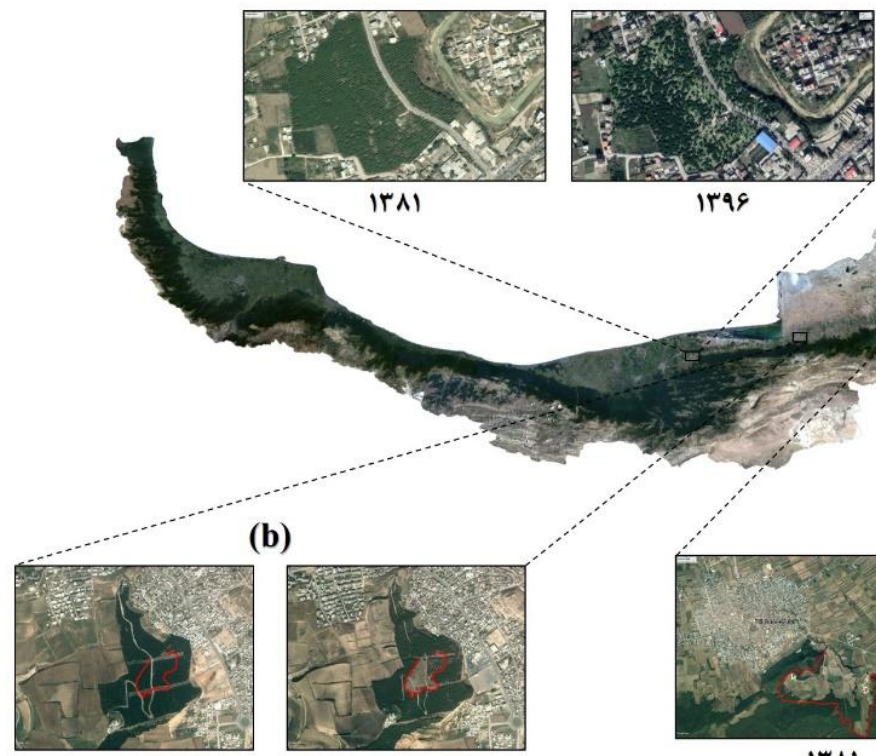

Iras

Iras

شكل 9: نمونهاى از تخريب جنكَل در (a) استان مازندران و (b, c) استان كَلستان

(c)

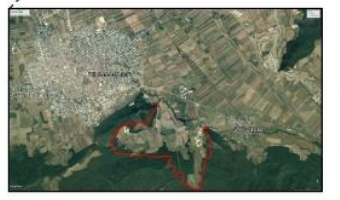

$|r \wedge|$

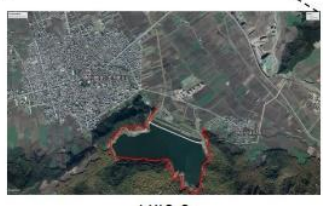

1799

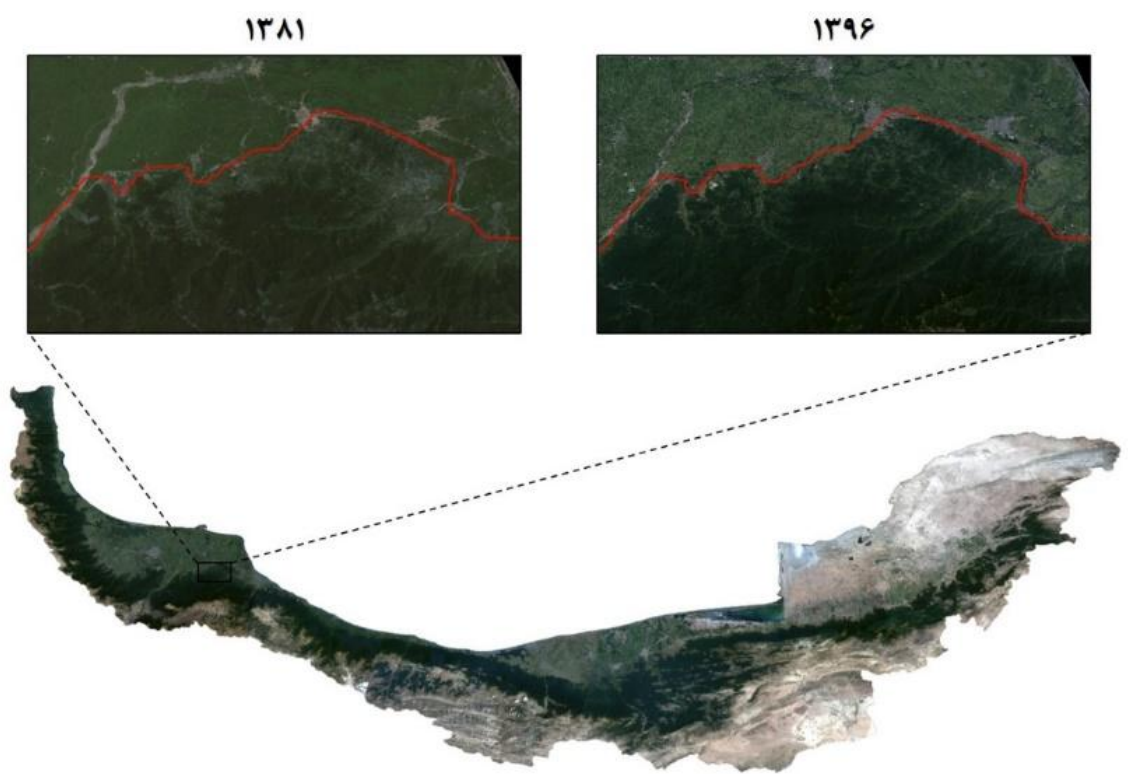

شكل \: نمونهاى از احياء جنغَل در استان كيلان

كرفته است نشان مىدهد اين مطالعات عمــتاً مقطعى

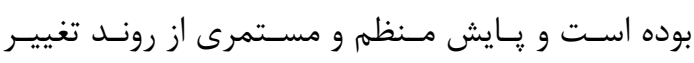

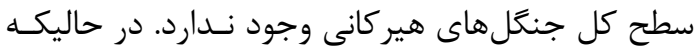
در اين تحقيق ميزان تغييرات جنگل هـاى هيركـانى در

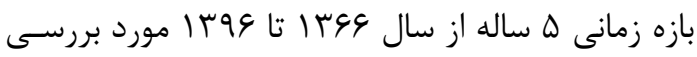

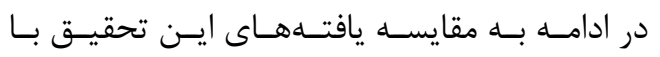

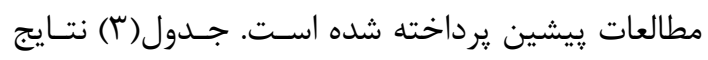

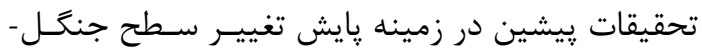

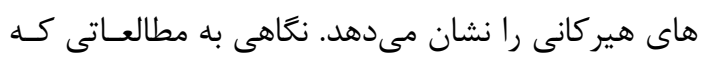
تاكنون در مطالعه و يايش جنگل هـاى هيركـانى انجـام 
اين وجود نتايج اين تحقيق با مطالعات FAO همخــوانى قرار كرفت. بنابراين نتايج اين تحقيق نمىتواند بصورت

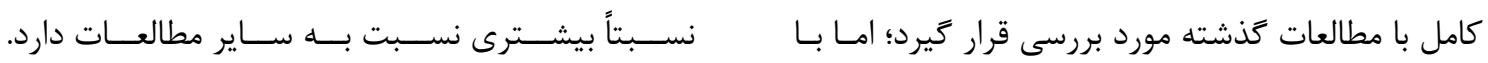
جدول بـ: مساحت جنغل هاى هير كانى در سالهاى مختلف براساس منابع رسمى [1]

\begin{tabular}{|c|c|c|c|c|}
\hline توضيح & مساحت (هكتار) & 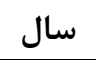 & 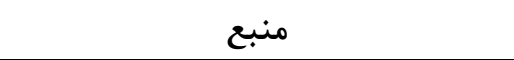 & 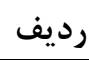 \\
\hline تاج-يوشش بيش از ه درصد & $|V V| \ldots$ & 1499 & استاندارد فائو & 1 \\
\hline تاج-يوشش بيش از له درصد & IAFYAMS & Irrr & سازمان جنكل ها، مراتع و آبخيزدارى كشور & r \\
\hline تاج-بوشش بيش از ه درصد & $|\wedge| \mid \vee \wedge \Lambda$ & irat & مؤسسه تحقيقات جنكَلها و مراتع كشور & r \\
\hline تاج-بوشش بيش از ه درصد & INFVAAG & Ir人t & 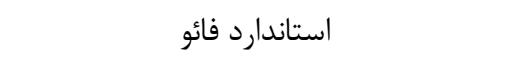 & f \\
\hline تاج-يوشش بيش از ه درصد & INFYAMS & 1 1 19 & استاندارد فائو & $\Delta$ \\
\hline تاج-يوشش بيش از ه درصد & $r \cdot V r r G \Lambda$ & Iraf & سازمان جنكل ها، مراتع و آبخيزدارى كشور & 4 \\
\hline تاج-يوشش بيش از ه درصد & 1949494 & irat & استاندارد فائو & $\checkmark$ \\
\hline تاج-بوشش بيش از ه درصد & 190.491 & 1790 & مؤسسه تحقيقات جنكَلها و مراتع كشور & $\wedge$ \\
\hline
\end{tabular}

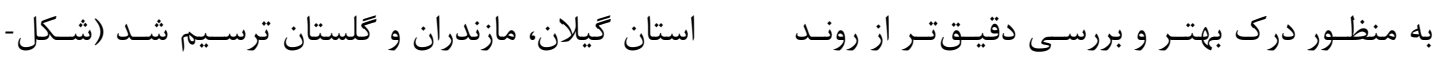

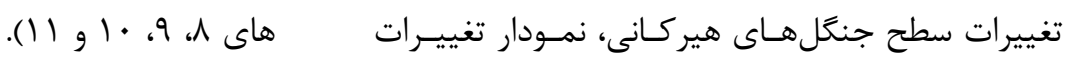

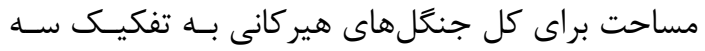
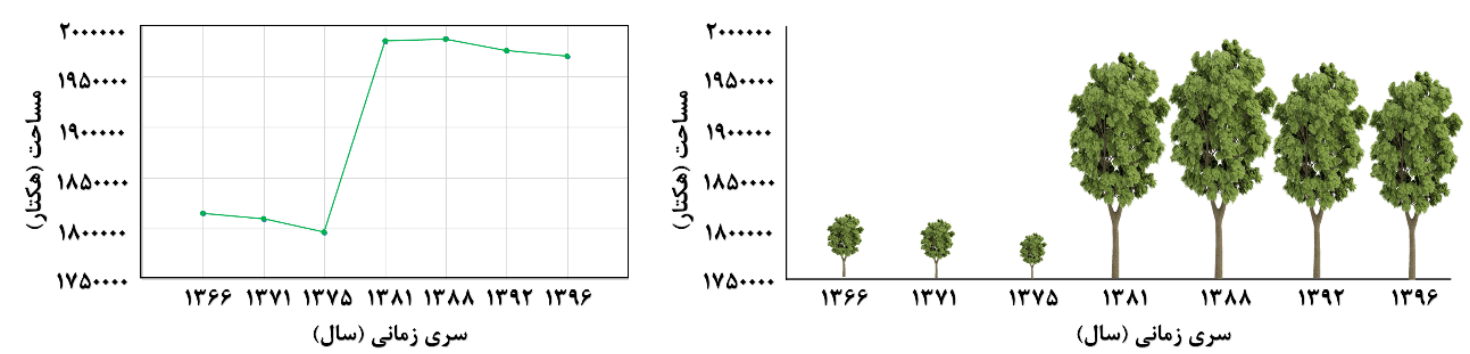

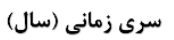

شكل ^: روند تغييرات سطح كل جنكَلهاى هير كانى
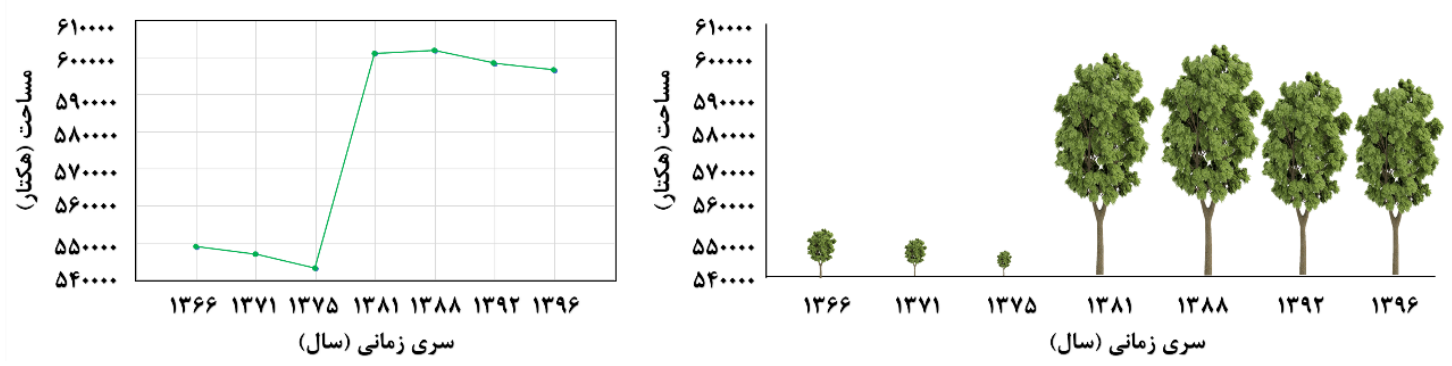

سرى زمانى (سال)

شكل 9: روند تغييرات سطح جنكَلهاى هير كانى در حوضه آبخيز استان كيلان 

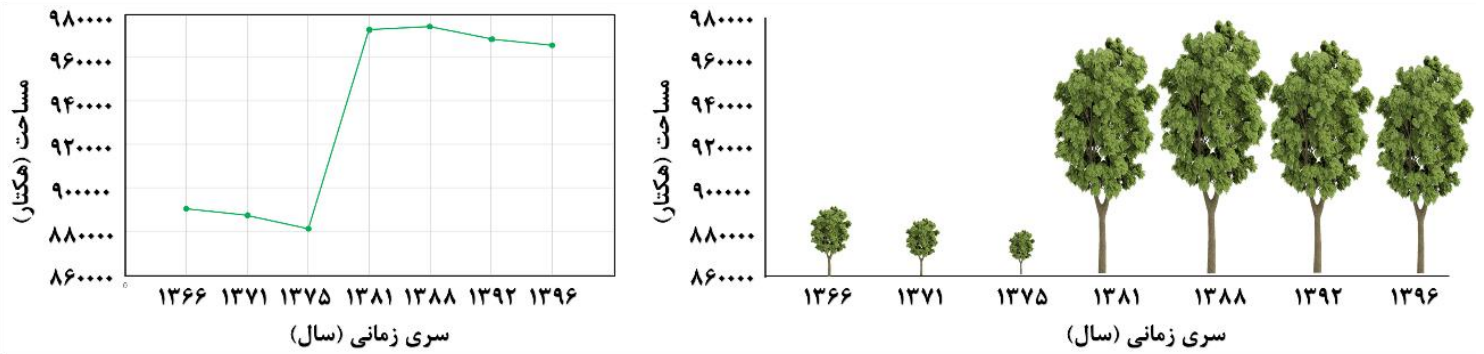

شكل •ا: روند تغييرات سطح جنغَلهاى هير كانى در حوضه آبخيز استان مازندران
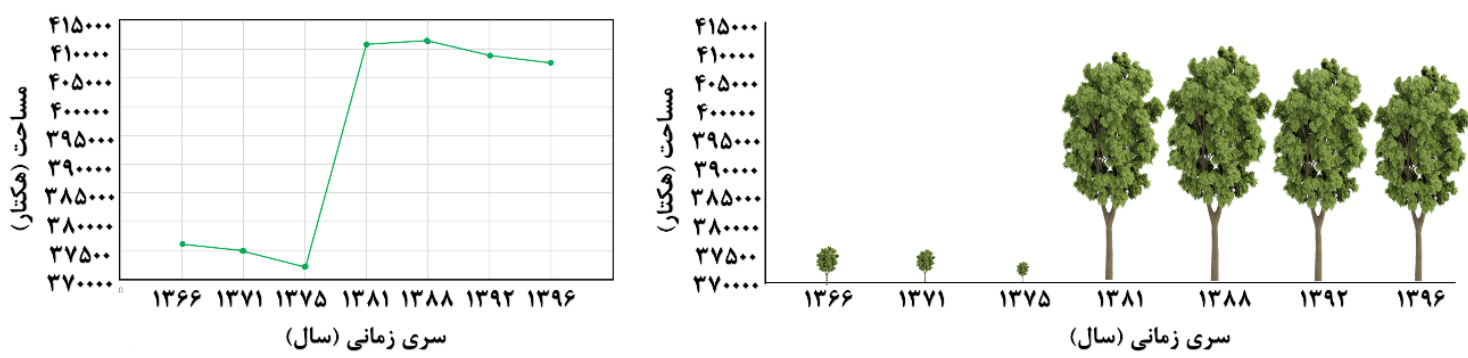

سرى زمانى (سال)

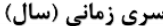

شكل Iا: روند تغييرات سطح جنغَلهاى هير كانى در حوضه آبخيز استان كَلستان

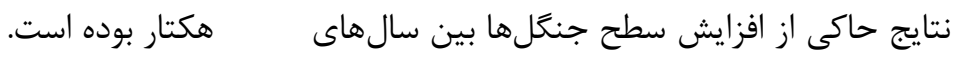

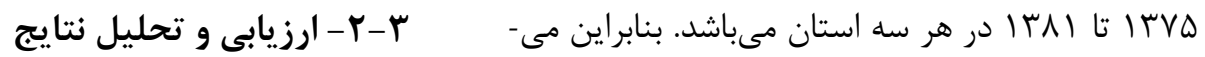

در اين بخش نتـايج حاصـل از مــدل FCD اوليسه و

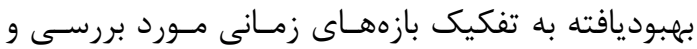

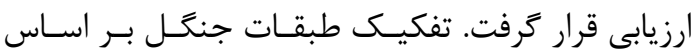

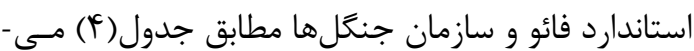

باشد.

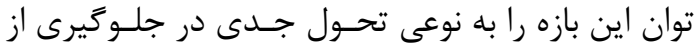

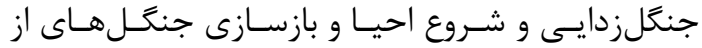

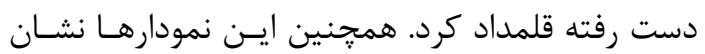

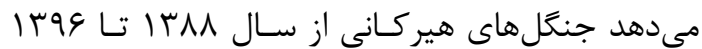

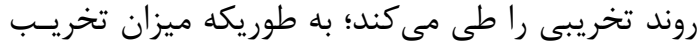

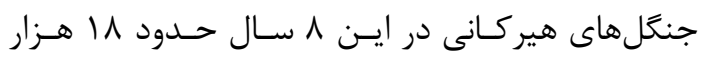

جدول F: طبقلبندى و تفكيك كلاسهاى جنكَل بر اساس استاندارد فائو و سازمان جنگل ها

\begin{tabular}{|c|c|c|c|c|c|}
\hline \multicolumn{3}{|c|}{ استاندارد طبقهبندى فائو } & \multicolumn{3}{|c|}{ استاندارد طبقهبندى سازمان جنـل ها } \\
\hline درصد تاج-يوشش & نام طبقه & رديف & درصد تاج-يوشش & نام طبقه & رديف \\
\hline$\cdot-\%$ & بدون جنگل & 1 & $1-\%$ & بدون جنگل & 1 \\
\hline $1 \cdot-\%$. & تنك & r & $\Delta-\%$. & بسيار تنك & $r$ \\
\hline$r \cdot-\%$. & نيمه انبوه & r & $1 \cdot-\%$. & تنك & r \\
\hline \multirow[t]{2}{*}{$v \cdot-\% 1 \cdots$} & انبوه & f & $c \cdot-\%$. & نيمه انبوه & f \\
\hline & & & $v \cdot-\% 1 \cdot$ & انبوه & $\Delta$ \\
\hline
\end{tabular}

حاليكه سازمان جنكل ها با افـزودن طبقـهـ بسـيار تنـــ

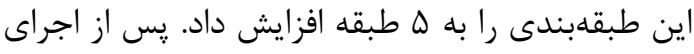

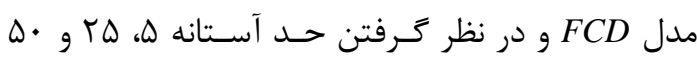

مطابق جدول(أ)، تفكيـك كـلاسهـاى جنـــل بـر

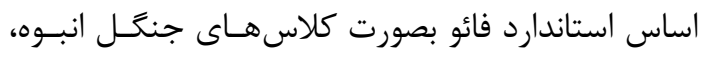

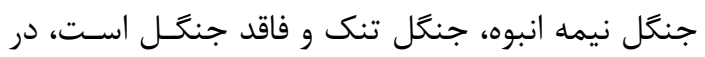


نقشه تاج-يوشش و دادههاى تسـت در طبقــه يكسـانى

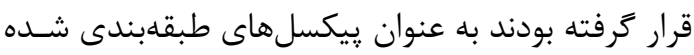

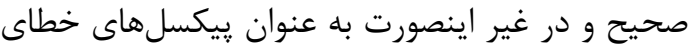
طبقهبندى مدل شناسايى و شمارش شـدند و مـاتريس خطاها تشكيل شد. تحليل آمارى نتايج بهدست آمده مبتنى بر تشكيل

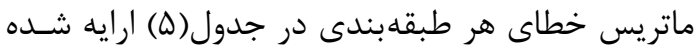

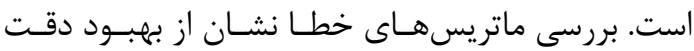

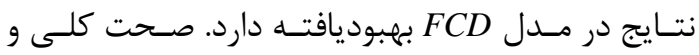

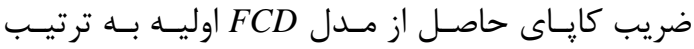

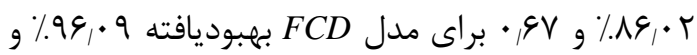

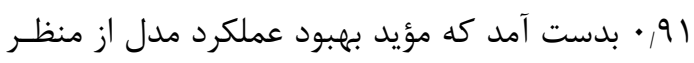

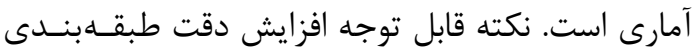
كلاس هاى جنكلى متراكم و فاقد جنكل است كه حاكى

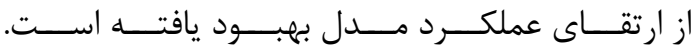

درصد جهت تفكيك طبقـهـهـاى جنَخـل انبـوه، جنَـــل نيمه انبوه، جنكل تنك و فاقد جنكل (مطابق اسـتاندارد

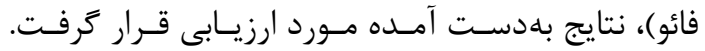

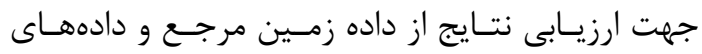

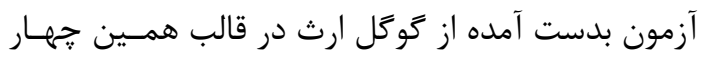
طبقه استفاده شد. نمونههاى آزمون مورد استفاده براى آداى

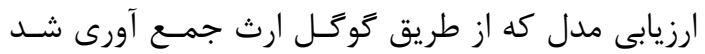

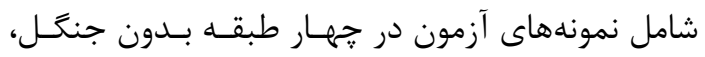

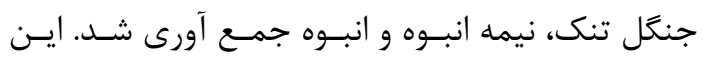

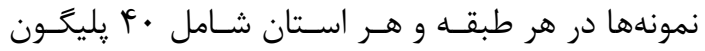
(حدوداً . . ه إليخون در كل محدوده مطالعاتى) با تعداد

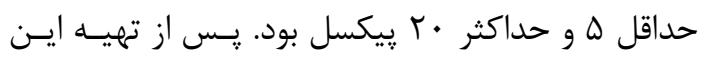
دادهها، مقايسه نقشه تاج-يوشش جنكَ حاصل حاصل از مدل

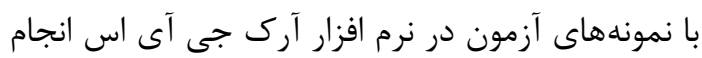

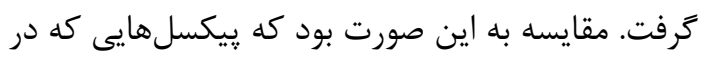

جدول ه: دقت نتايج ييادهسازى مدل FCD اوليه، FCD بهبوديافته مرحله اول و FCD بهبوديافته نهايى

\begin{tabular}{|c|c|c|}
\hline ضريب كايا & صحت كلى (٪) & مدل \\
\hline$\cdot, \phi \wedge$ & $\Lambda \varepsilon_{i} \cdot r$ & FCD اوليه \\
\hline$\cdot \wedge \Lambda$ & $q 4, g r$ & FCD بهبوديافته مرحله اول \\
\hline$\cdot 91$ & 94,9 & FCD بهببوديافته نهايى \\
\hline
\end{tabular}

FCD بهبوديافته در بازههـاى زمـانى مختلـف را نشـان مى دهد. مطابق اين جدول، صحت كلى و ضريب كايا در

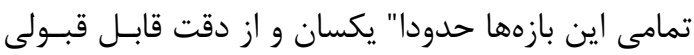

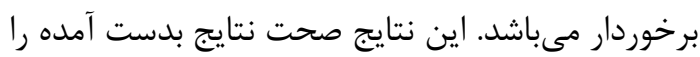

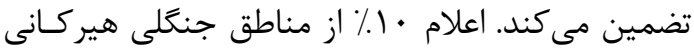

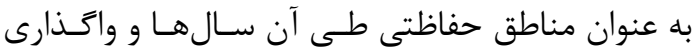

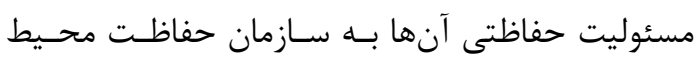
زيست امرى است كه سبب خوداحيايى جنكل هاى واقع إنعان در مناطق حفاظت شـده گرديـد. ايسن مســأله را طـرح

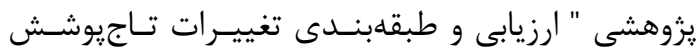

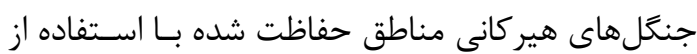

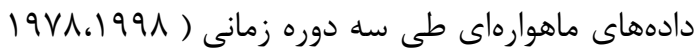

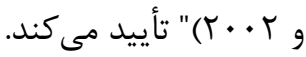

مطابق جدول(ه)، مدل FCD اوليه عملكرد مناسبى در تفكيك تاج-يوشـش جنَــل از منـاطق كشـاورزى و سبزينگى غيرجنَلى نداشته است. اين جـالش را مـدل بهبود يافته نهايى تا حدود زيادى جبــران كـرده اسـت. شكل(T) (T) نماى نزديكـتر نقشـهـ تـاج-يوشـش بدست

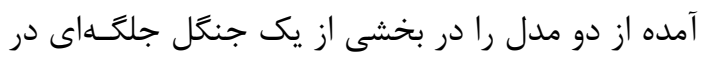
منطقه نشان مى دهد. در ادامه ارزيابى مربـوط بـه نتــايج حاصـل از مـدل FCD

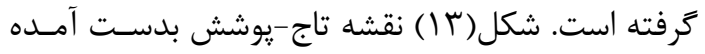

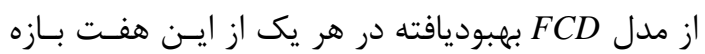
زمانى را نشان مى مهد. جدول(9) صحت كلى و ضريب كاياى حاصـل از مــل 


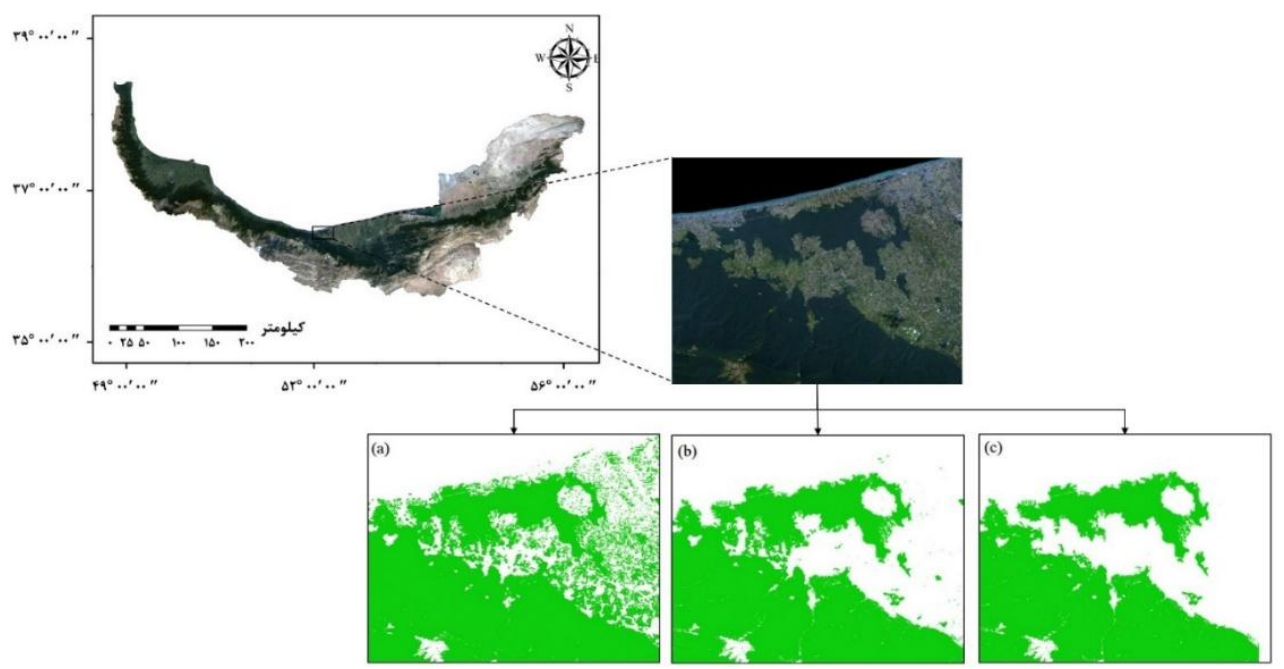

شكل ז/: نماى نزديك نقشه تاج-يوشش مدل FCD (a) FCD (b) بهبوديافته مرحله اول و FCD (c) بهبوديافته نهايى

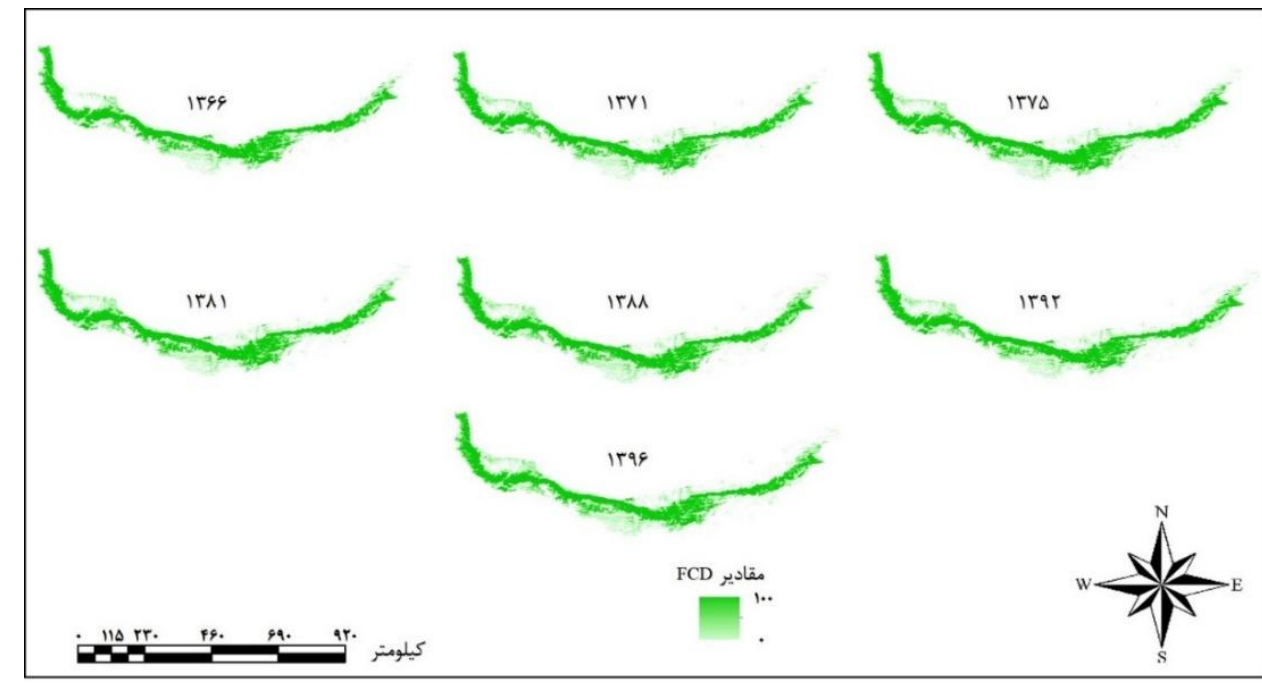

شكل سٓا: نقشه تاج-يوشش بدست آمده از مدل FCD بهبوديافته از جنغَلهاى هيركانى در بازههاى زمانى مختلف

\begin{tabular}{|c|c|c|}
\hline ضريب كايا & صحت كلى (\%) & بازه زمانى \\
\hline$\cdot 91$ & $90, p^{k}$ & اول \\
\hline .91 & 90,91 & دوم \\
\hline$\cdot 9$. & 90,19 & سوم \\
\hline .91 & $9 \Delta, r)$ & جهارم \\
\hline .91 & $q \Delta, \vee q$ & ينجم \\
\hline$\cdot 9$. & 90,91 & ششم \\
\hline$\cdot 99$ & 98,9 & هفتم \\
\hline
\end{tabular}




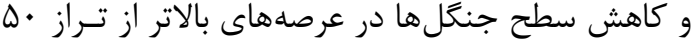
متر مواجه هستيم و اين مىتواند حاكى از تغيير رويكرد

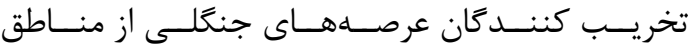
ياييندست به سمت مناطق و عرصههاى بالادست باشد.

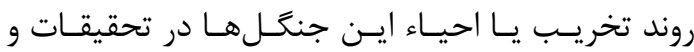

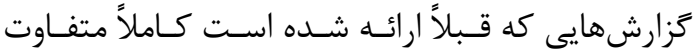
است. نتايـج بهدسـت آمـده از برخى از اين طـرحهــاى

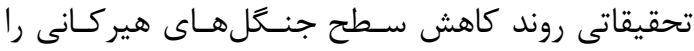

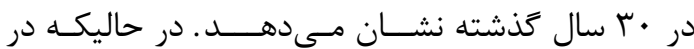
برخى ديكر از اين طرحها اين روند افزايشى بيـان شـده

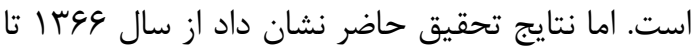

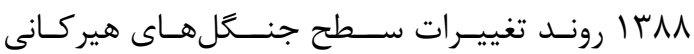

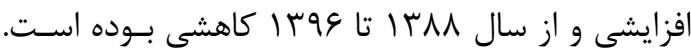
اين تناقض بين نتايج كزارشهاى مختلف به اين دليـل

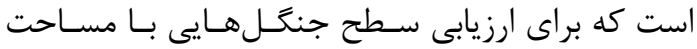

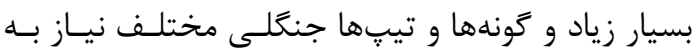
تصاوير بـا قـدرت تفكيـك مكـانى بسـيار بـالا و انجـام

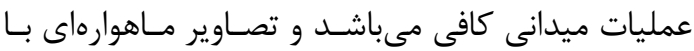
دسترسى رايكان و قدرت تفكيك مكـانى يـايين كـه در تحقيقات قبلى و تحقيق حاضر مورد استفاده قرار گرفت

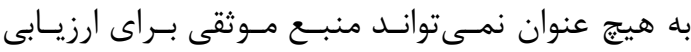
تخريب يا احياء جنكلها باشد.

[1] Kh. Mirakhorlou and R. Akhavan "Area changes of Hyrcanian Forests during 2004 to 2016", Agricultural Research Education and Extension Organization (AREEO), 69, 121-133, 2016.

[2] O.W. Tsui, N.C. Coops, M.A. Wulder, P.L. Marshall, and A. Cardle, "Using multifrequency radar and discrete-return LiDAR measurements to estimate aboveground biomass and biomass components in a coastal temperate forest", ISPRS Journal of Photogrammetry and Remote Sensing, 69, 121-133, 2012.

[3] D. LU, "A Review-The potential and challenge of remote sensing-based biomass estimation", International Journal of

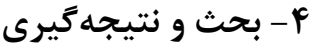

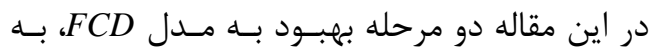
منظور كاهش ضعف اين مدل در تفكيـك يوشـشهـاى

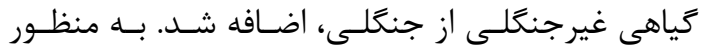

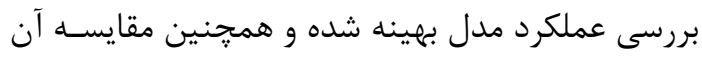

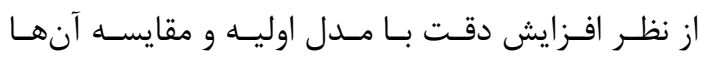

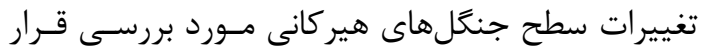

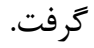

مقايسه دقت بدست آمده از نتايج نشان داد صحت

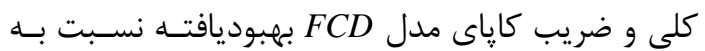

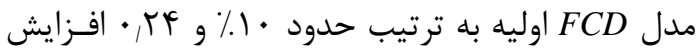
داشت. اين افزايش دقت به اين دليل است كه با افزودن

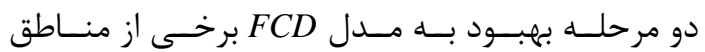

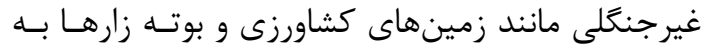

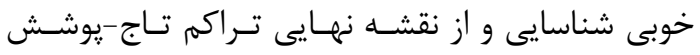
جنكل حذف شدهاند. همجنين نتايج حاصل از تغييرات سطح جنگل هـاى

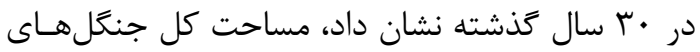

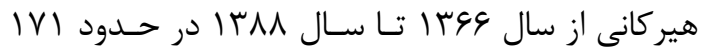

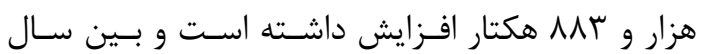

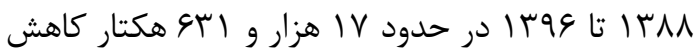
داشته است. به ديكر بيان طى يك دهه اخير با تخريـب

\section{مراجع}

Remote Sensing, 27(7), 1297-1328, 2006.

[4] O.W. Tsui, N.C. Coops, M.A. Wulder and P.L. Marshall, "Integrating airborne LiDAR and spaceborne radar via multivariate kriging to estimate aboveground biomass", Remote Sensing of Environment, 139, 340-352, 2013.

[5] B. Mosavi, "Comparison of high resolution (Quickbird) and medium resolution (Landsat8-OLI) satellite images capability in estimation of trees aboveground biomass", A thesis of Master student, Gorgan University of Agriculture and Natural Resources, 2015.

[6] Gh. Ronoud, "Estimating aboveground 
woody biomass of Fagus orientalis stands in Hyrcanian forest of Iran using Landsat 8 satellite data (Case study: Khyroud forest)", A thesis of Master student, University of Tehran, 2016.

[7] S. Attarchi, "Complex land cover classification and physical properties retrieval of the Hyrcanian forest: A MultiSource Remote Sensing approach", A thesis of PhD student, University of $T U$ Bergakademie Freiberg, 2014.

[8] S. Attarchi and R. Gloaguen, "Improving the Estimation of Above Ground Biomass Using Dual Polarimetric PALSAR and ETM+ Data in the Hyrcanian Mountain Forest (Iran)", Remote Sensing of Environment, 6(5), 3693-3715, 2014.

[9] J. Mohammadi, S. Shataee, M. Namiranian, and E. Noesset, "Modeling biophysical properties of broad-leaved stands in the Hyrcanian forests of Iran using fused airborne laser scanner data and ultraCam$D$ images", International Journal of Applied Earth Observation and Geoinformation, 61, 32-45, 2017.

[10] A. Raei, P. Pahlavani and M. Hasanlou, "Determining effective factors on forest fire using the compound of geographically weighted regression and genetic algorithm, a case study: Golestan, Iran”, Journal of Geospatial Information Technology, 61, 32-45, 2016.

[11] S.C. Pal, R. Chakrabortty, S. Malik, and B. Das, "Application of forest canopy density model for forest cover mapping using LISSIV satellite data: a case study of Sali watershed, West Bengal", Modeling Earth Systems and Environment, 4(2), 853-865, 2018.

[12] R.S. Sharma and T.P. Singh, "Forest Canopy Density Assessment Using High Resolution LISS-4 Data in Yamunanagar District, Haryana”, International Archives of the Photogrammetry, Remote Sensing and Spatial Information Sciences, 42, 5-11, 2018.

[13] A.C. Fitrianto, A. Darmawan, $K$.
Tokimatsu, and K. Yoshikawa, "Spatial distribution of empty fruit bunch production as potential electric resource using remote sensing technique”, Energy Procedia, 158, 3565-3571, 2019.

[14] A. Shaholi, M. Pirbavaghar and P. Fatehi, "Forest Canopy Density Assessment Using FCD model: a case study of Marivan forests", Journal of RS and GIS in Natural Resources, 6, 21-28, 2014.

[15] A. Rikimaru, "TM Data Processing Guide for forest Canopy Density Mapping and Monitoring Model", presented at Utilization of Remote Sensing in Site Assessment and Planning for Rehabilitation of Logged-over Forest, Bangkok, Thailand, 1996.

[16] M.S. Jamalabad, "Forest canopy density monitoring using satellite images", presented at ISPRS Congress, Istanbul, Turkey, 2004.

[17] Z. Azizi et al, "Forest canopy density estimating using satellite images”, International Archives of the Photogrammetry, Remote Sensing and Spatial Information Sciences, 8, 5-11, 2008.

[18] C. Huang, L. Yang, B. K. Wylie, and C. Homer, "A strategy for estimating tree canopy density using Landsat 7 ETM+ and high-resolution images over large areas", International Journal of Applied Earth Observation and Geoinformation, 61, 3245, 2001.

[19] SZ. Hosseini, M. Kappas, and P. Propastin, "Estimating Relationship between Vegetation Dynamic and Precipitation in Central Iran", presented at Toledo conference, Spain, 2011.

[20] G. Yin, Z. Hu, X. Chen and T. Tiyip, "Vegetation dynamics and its response to climate change in Central Asia”, Journal of Arid Land, 8(3), 375-388, 2016.

[21] R. Sharma, K. Hara and R. Tateishi, "Developing forest cover composites through a combination of Landsat-8 optical and Sentinel-1 SAR data for the 
نشريه علمى يزووهشى - مهندسى فناورى اطلاعات مكانى

سال هشتم • شماره دوم • تابستان 9 ه س

visualization and extraction of forested areas", Journal of Imaging, 4(9), 105, 2018.

[22] FAO (Food and Agriculture Organization), 2005. Global Forest Resources Assessment 2005, (Iran report). Rome, 2005, P41. 


\title{
Introducing the improved Forest Canopy density (FCD) model for frequent assessment of Hyrcanian forest
}

\author{
Masoud Taefi Feijani ${ }^{1 *}$, Saeed Azadnejad ${ }^{2}$ \\ 1- Instructor, Research Scientist, Aerospace Research Institute Space Systems Research Group. \\ 2-Researcher, Research Scientist, Aerospace Research Institute Space Systems Research Group.
}

\begin{abstract}
Mapping of forest extent is a prerequisite to acquire quantitative and qualitative information about forests and to formulate management and conservation strategies. forest canopy density (FCD) model is one of the useful $R S$ methods for forest mapping using satellite images. One of the most serious challenges in FCD model is the weakness in the calculation of canopy density in low density forests as well as plain forests. Due to the existence of chlorophyll in croplands, shrubs, pastures, etc., FCD model has difficulty to determinate the forests areas from the other mentioned land cover. Hence, this paper is focused on improving the performance of FCD model to overcome this limitation. This improvement yield by adding a new forest color composite index (FCCI) and removing non-forest vegetation using the average kernel and DEM regard to standard forest definition. In this study, in order to implement and evaluate the performance of the improved model, time series of Landsat images acquired from USGS Landsat standard level-2 products archive. In this study, Landsat time series images acquired from USGS Landsat standard level-2 products were used to estimate forest canopy density in Hyrcanian forests of northern Iran. The results indicated the higher accuracy of the proposed model. Moreover, overall accuracy and kappa index of the model were $10 \%$ and $24 \%$ superior to initial model, respectively. As a second objective, in order to implement and evaluate the performance of the improved model, canopy changes of the Hyrcanian forests were also examined. In general, the results of this study showed that the total area of Hyrcanian forest increased from 154,272 hectares from 1987 to 2009. Mazandaran, Gilan and Golestan provinces contributed 75,070, 47,615 and 31,567 hectares respectively. In addition, the results showed that the area of Hyrcanian forests decreased by 17,631 hectares between 2009 and 2017.

Key words: Hyrcanian forest, Forest canopy density model, Landsat time series data, plain forests.
\end{abstract}

Correspondence Address: Tehran, Shahrak-e-Gharb, Iranzamin Ave ,Mahestan St, 15th Alley.

Tel : +982188366030

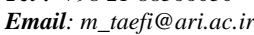

